\title{
Ambient fine particulate matter and ozone exposures induce inflammation in epicardial and perirenal adipose tissues in rats fed a high fructose diet
}

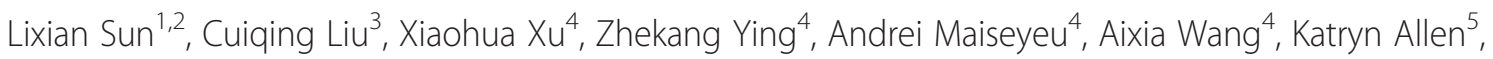
Ryan P Lewandowski ${ }^{5}$, Lori A Bramble ${ }^{5}$, Masako Morishita ${ }^{6}$, James G Wagner ${ }^{5}$, J Timothy Dvonch ${ }^{6}$, Zhichao Sun ${ }^{6}$, Xiaowei Yan ${ }^{1}$, Robert D Brook ${ }^{7}$, Sanjay Rajagopalan ${ }^{4}$, Jack R Harkema ${ }^{5}$, Qinghua Sun ${ }^{4 *}$ and Zhongjie Fan ${ }^{1 *}$

\begin{abstract}
Background: Inflammation and oxidative stress play critical roles in the pathogenesis of inhaled air pollutantmediated metabolic disease. Inflammation in the adipose tissues niches are widely believed to exert important effects on organ dysfunction. Recent data from both human and animal models suggest a role for inflammation and oxidative stress in epicardial adipose tissue (EAT) as a risk factor for the development of cardiovascular disease. We hypothesized that inhalational exposure to concentrated ambient fine particulates (CAPs) and ozone $\left(\mathrm{O}_{3}\right)$ exaggerates inflammation and oxidative stress in EAT and perirenal adipose tissue (PAT).
\end{abstract}

Methods: Eight- week-old Male Sprague-Dawley rats were fed a normal diet (ND) or high fructose diet (HFr) for 8 weeks, and then exposed to ambient AIR, CAPs at a mean of $356 \mu \mathrm{g} / \mathrm{m}^{3}, \mathrm{O}_{3}$ at $0.485 \mathrm{ppm}$, or CAPs $\left(441 \mu \mathrm{g} / \mathrm{m}^{3}\right)+$ $\mathrm{O}_{3}$ (0.497 ppm) in Dearborn, Ml, 8 hours/day, 5 days/week, for 9 days over 2 weeks.

Results: EAT and PAT showed whitish color in gross, and less mitochondria, higher mRNA expression of white adipose specific and lower brown adipose specific genes than in brown adipose tissues. Exposure to CAPs and $\mathrm{O}_{3}$ resulted in the increase of macrophage infiltration in both EAT and PAT of HFr groups. Proinflammatory genes of Tnf-a, Mcp-1 and leptin were significantly upregulated while IL-10 and adiponectin, known as antiinflammatory genes, were reduced after the exposures. CAPs and $\mathrm{O}_{3}$ exposures also induced an increase in inducible nitric oxide synthase (iNOS) protein expression, and decrease in mitochondrial area in EAT and PAT. We also found significant increases in macrophages of $\mathrm{HFr}_{-} \mathrm{O}_{3}$ rats. The synergetic interaction of $\mathrm{HFr}$ and dirty air exposure on the inflammation was found in most of the experiments. Surprisingly, exposure to CAPs or $\mathrm{O}_{3}$ induced more significant inflammation and oxidative stress than co-exposure of CAPs and $\mathrm{O}_{3}$ in EAT and PAT.

Conclusion: EAT and PAT are both white adipose tissues. Short-term exposure to CAPs and $\mathrm{O}_{3}$, especially with high fructose diet, induced inflammation and oxidative stress in EAT and PAT in rats. These findings may provide a link between air-pollution exposure and accelerated susceptibility to cardiovascular disease and metabolic complications.

Keywords: Particulate matter, Ozone, Epicardial adipose tissue, Perirenal adipose tissue, Inflammation, Oxidative stress

\footnotetext{
* Correspondence: Sun.224@osu.edu; zhifan@hotmail.com

${ }^{4}$ Davis Heart and Lung Research Institute, The Ohio State University, Columbus, Ohio, USA

'Department of Cardiology, Peking Union Medical College Hospital, Peking Union Medical College \& Chinese Academy of Medical Science, Beijing,

China

Full list of author information is available at the end of the article
} 


\section{Background}

Adipose inflammation is a characteristic hallmark of Type II diabetes-obesity states characterized by insulin resistance. The term "metaflammation" is widely used to describe the close dependence of metabolic abnormalities to inflammation in the visceral fat tissues. The inflammation in adipose depots has been widely linked to systemic abnormalities including disturbances in glucose homeostasis, lipid abnormalities and accelerated development of cardiovascular disease. We and others have described recent findings that have linked airpollution exposure in animal models to the development of insulin resistance and inflammation [1]. A characteristic hallmark in these studies was the development of adipose inflammation in visceral fat tissues characterized by the infiltration of innate immune cells and proinflammatory gene expression. Additionally, we have demonstrated a downregulation of brown adipose tissue specific genes such as uncoupling protein $\left(U_{c p}\right)-1$ and an upregulation of genes specific to white adipose tissue by air pollution exposure. White adipose tissue is highly adapted to store excess energy as triglycerides, while brown adipose tissue functions to dissipate chemical energy in the form of heat [2]. Recent studies have called attention to a role for epicardial adipose tissue (EAT) inflammation as an additional determinant of inflammation and susceptibility to cardiovascular disease in patients with obesity and metabolic syndrome [3]. EAT is an unusual visceral fat depot with anatomical and functional contiguity to the myocardium and coronary arteries that may serve a unique role and thus may differ from other visceral fat tissues depots [3,4]. EAT is also a source of multipotent stem or progenitor-like cell populations, which are deemed to be involved in the tissue repair and in the pathogenesis of cardiovascular disease. A growing body of evidence supports a facilitatory role for EAT inflammation in cardiovascular disease [5-8]. Clinically, the inflammation and oxidative stress of perirenal adipose tissue (PAT) may have close relation with the development of cardiovascular diseases, especially systemic hypertension. To what extent inflammation and oxidative stress in EAT and PAT is present in the context of high fructose diet and simultaneous exposure to inhaled particulates and gases has not been investigated. In this study we used a relevant rat model of high-fructose ingestion and exposed the animals to a mixture of concentrated ambient fine particulates (CAPs) and ozone $\left(\mathrm{O}_{3}\right)$ to assess the inflammation and oxidative stress.

\section{Results}

\section{Whole-body exposure data}

The average CAPs concentrations were $356 \pm 261 \mu \mathrm{g} / \mathrm{m}^{3}$ (mean \pm standard deviation; ambient $=13.9 \mu \mathrm{g} / \mathrm{m}^{3}$ ) for the group exposed to CAPs alone, and $441 \pm 196 \mu \mathrm{g} / \mathrm{m}^{3}$ (ambient $=12.5 \mu \mathrm{g} / \mathrm{m}^{3}$ ) for CAPs and $\mathrm{O}_{3}$ co-exposure. The average chemical composition of CAPs during the exposure periods is shown in Figure 1. As shown, the CAPs constituents were dominated by organic carbon and sulfate, which is typical for the summer months at this monitoring site and in much of the upper Midwest [9]. Average $\mathrm{O}_{3}$ concentrations of $0.485 \pm 0.042 \mathrm{ppm}$ were achieved for the group exposed to $\mathrm{O}_{3}$ alone, with a concentration of $0.497 \pm 0.030 \mathrm{ppm}$ generated during CAPs and $\mathrm{O}_{3}$ co-exposure.

\section{Body weight measurement}

Table 1 illustrates the changes in body weight of the rats before and after the exposure to the $\mathrm{CAP}_{\mathrm{S}}$ and $\mathrm{O}_{3}$ in ND and HFr groups, which had no significant differences $(p>0.05)$. In the current study, there was $10 \%-15 \%$ difference in body weight before and after the exposures. The "before exposure" body weight was measured in the laboratories at MSU before transporting rats to the field site seven days before exposures.

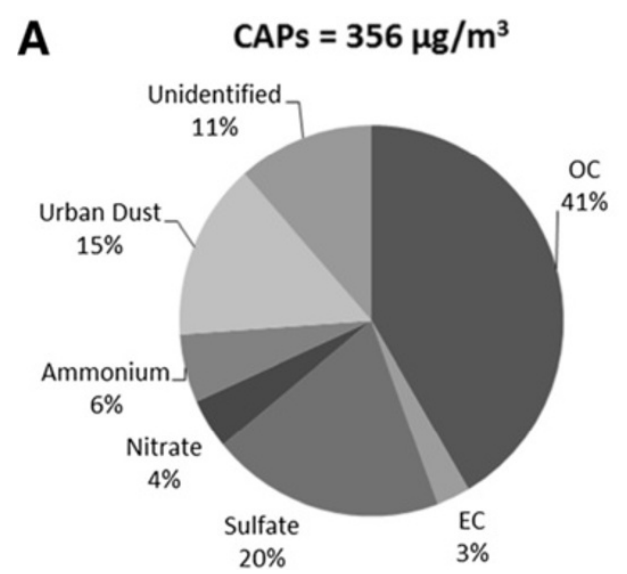

B $\quad$ CAPs $=441 \mu \mathrm{g} / \mathrm{m}^{3}$

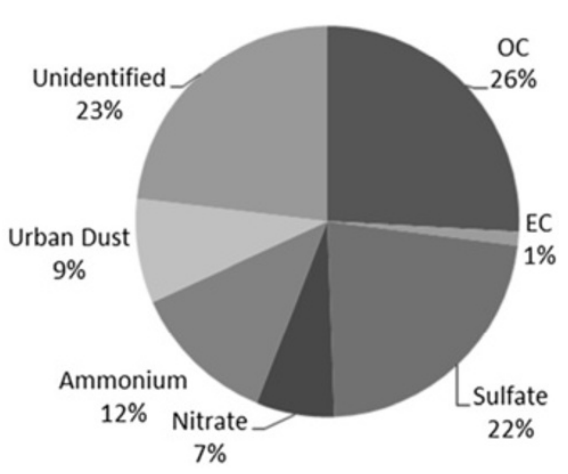

Figure 1 Major compositions of CAPs during exposure periods. Particles were collected during the exposures to CAPs alone (A) and CAPs $+\mathrm{O}_{3}$ (B) and analyzed as described in Methods. 
Table 1 Body weight changes before and after exposure to $\mathrm{CAPs} / \mathrm{O}_{3}$ (gram, mean $\pm \mathrm{SEM}$ )

\begin{tabular}{lccc}
\hline Diet \& exposure & Baseline & After normal or high -fructose diet & After exposures \\
\hline ND-AIR & $419.00 \pm 11.96$ & $570.88 \pm 20.95$ & $517.63 \pm 19.53$ \\
ND-CAPs & $433.63 \pm 7.26$ & $525.75 \pm 16.86$ & $503.88 \pm 13.37$ \\
$\mathrm{ND}_{3} \mathrm{O}_{3}$ & $439.63 \pm 8.05$ & $537.00 \pm 12.69$ & $523.88 \pm 13.67$ \\
$\mathrm{ND}-\mathrm{CAPS}+\mathrm{O}_{3}$ & $409.50 \pm 12.90$ & $546.50 \pm 16.07$ & $492.75 \pm 17.45$ \\
$\mathrm{HFr}-\mathrm{AlR}$ & $394.86 \pm 8.16$ & $545.00 \pm 14.86$ & $507.29 \pm 14.73$ \\
$\mathrm{HFr}-\mathrm{CAPs}$ & $436.00 \pm 11.95$ & $561.00 \pm 22.02$ & $527.25 \pm 24.31$ \\
$\mathrm{HFr}-\mathrm{O}_{3}$ & $443.25 \pm 10.81$ & $558.25 \pm 14.67$ & $531.75 \pm 16.60$ \\
$\mathrm{HFr}-\mathrm{CAPS}+\mathrm{O}_{3}$ & $393.14 \pm 9.39$ & $531.57 \pm 18.60$ & $516.29 \pm 23.03$ \\
\hline
\end{tabular}

Notes: ND normal diet, AIR ambient air, CAPs concentrated ambient fine particulates, $\mathrm{O}_{3}$ ozone, $\mathrm{HFr}$ high-fructose diet, $\mathrm{N}=7-8$.

Contributing factors to body weight changes include the stresses from being transported to the exposure facility and the actual exposures per se, along with no access to chow and water during the $8 \mathrm{~h}$-exposures per diem. Rats were fasted an additional 3-4 hours after the last exposure during transportation to the MSU laboratories.

\section{Characteristics of adipose tissues}

H\&E staining and TEM analysis of in situ mitochondria

To determine the morphology of the adipocytes and to clarify whether the EAT and PAT demonstrates white or brown adipose characteristics, we performed H\&E staining and TEM in EAT and PAT, and found that the adipocytes of EAT (Figure 2A, 2E) and PAT (Figure 2B, 2F) were similar in shape to those of visceral fats (WAT) (Figure 2C, 2G) but quite different from interscapular fat (BAT) (Figure 2D, 2H). The area of adipocytes of EAT $\left(1,029.0 \pm 43.0 \mu \mathrm{m}^{2}\right), \operatorname{PAT}\left(5,133.0 \pm 208.3 \mu \mathrm{m}^{2}\right)$ and WAT $\left(4,870.0 \pm 197.4 \mu^{2}\right)$ in the ND groups was much larger than that in BAT $\left(248.1 \pm 8.1 \mu^{2}\right)(p<0.001)$. The adipocytes of EAT, PAT and WAT had single and eccentric nuclei and unilocular droplets, while BAT had multiple and central nuclei and plurilocular droplets. In addition, adipocytes in EAT were much smaller than those in PAT and WAT $(p<0.001)$. Of note, adipocytes of WAT were hypertrophic in response to $\mathrm{HFr}$ feeding (Figure 2G), which was also found to certain extent in EAT (Figure 2E) and PAT (Figure 2F). Figure 3 demonstrated that there were less mitochondria in EAT and PAT than in BAT $(p<0.001)$.

\section{WAT and BAT specific gene expressions in adipose tissues}

WAT and BAT specific gene expressions in EAT and PAT were analyzed by quantitative real-time PCR. BAT specific gene expressions, such as Ucp1, Pgc1 $\alpha$, Cidea, C/ebp $\beta$ and Dio2, were found several hundreds of folds lower in EAT and PAT than that in BAT $(p<0.001$, Figure 4$)$, while the WAT specific gene expressions (Dpt and Hoxc9) in EAT and PAT were higher than that in BAT ( $p<0.05$, Figure 5). Another interesting observation in this study was that BAT specific gene expressions of Ucp1, Pgcl, and Cidea in
EAT were nearly 10 folds higher than that in PAT and WAT $(p<0.001$, Figure 4$)$. Furthermore, the relative mRNA levels of WAT specific gene $(D p t)$ in EAT were lower than that in PAT and WAT $(p<0.01$, Figure 5$)$, but Hoxc9 was much higher in EAT and PAT than that in BAT $(p<0.001$, Figure 5). Additionally, the relative mRNA level of Igfbp3 in WAT, also a WAT specific gene, is significantly higher than that in BAT $(p<0.001$, Figure 5). The characteristics of different adipose tissues including EAT, PAT, WAT, and BAT are summarized in Table 2.

\section{BAT and WAT specific gene expressions in EAT and PAT after exposure to $\mathrm{CAP}_{5}$ and $\mathrm{O}_{3}$ $B A T$ specific gene expression alteration}

To test if exposure to CAPs and $\mathrm{O}_{3}$ led to the gene expression alteration in EAT and PAT, we performed quantitative real-time PCR analysis. We found that $\mathrm{HFr}$ diet and dirty air exposure had synthetic interaction on the gene changes of Ucp1,Pgc1 $\alpha$ and Cidea in EAT and PAT (Figure 6). Figure 6 illustrates that BAT-specific gene levels of $U c p 1$ was significantly down-regulated in ND groups in EAT and PAT $(p<0.05)$, while Pgc1 $\alpha$ and Cidea were not significantly down-regulated in ND groups. However, the genes expression of Ucp1,Pgc1 $\alpha$ and Cidea were all markedly decreased, both in EAT and PAT, in HFr groups after the exposure of CAPs and $\mathrm{O}_{3}$ $(p<0.001$, Figure 6A, 6B). Specifically, HFr-CAPs group showed the lowest BAT-specific gene expressions compared with the other 7 groups (Figure 6A, 6B). As shown in Figure 6, the BAT-specific gene expression alterations had similar trend in PAT as in EAT, except that Ucp1, $P g c-1 \alpha$ and Cidea expressions were about 10 folds lower in PAT than that in EAT. As to C/Ebpßand Dio2 genes expression, there were no significant difference in EAT and PAT in both ND and HFr groups after the exposures $(p>0.05$, Figure 6).

\section{WAT specific gene expression alteration}

It was shown that HFr diet and dirty air exposure had synthetic interaction on the gene changes of $D p t$ and Hoxc9 in EAT and PAT (Figure 7). As shown in Figure 7, 


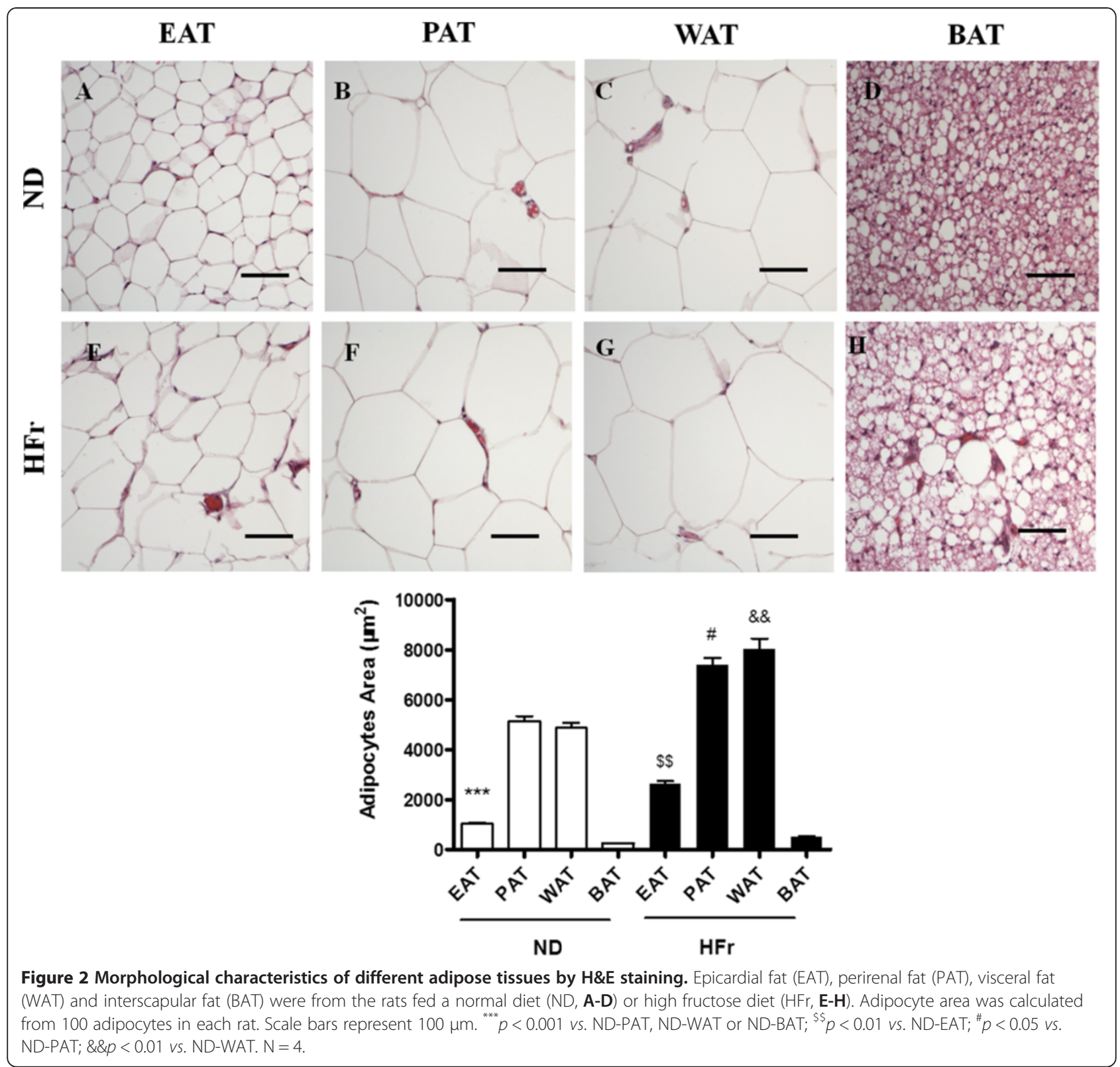

Dpt and Hoxc9 expressions were significantly decreased after exposure to CAPs and/or $\mathrm{O}_{3}$ in EAT (Figure 7A) and PAT (Figure 7B) in the rats, especially in HFr groups $(p<0.01)$. As to Igfbp3 expression, there was less significant downregulation in EAT and PAT in HFrCAPs groups $(p<0.05$, Figure 7$)$. In addition, Dpt gene level did not show significant decrease in the coexposure of CAPs and $\mathrm{O}_{3}$ vs. CAPs or $\mathrm{O}_{3}$ in $\mathrm{HFr}$ groups in $\operatorname{EAT}(p<0.05$, Figure 7A).

\section{Systemic inflammation and oxidative stress in EAT and PAT} Adiponectin levels

We performed the ELISA to measure adiponectin levels in the supernatants of EAT and PAT. As shown in
Table 3, there was no significant difference of the adiponectin levels among the eight groups in either EAT or PAT after different exposures.

\section{Macrophage infiltration}

Figure 8 illustrated representative images of CD68 (a marker of tissue macrophages in rats) staining in the adipose tissues, which showed significant increase of adipose tissue macrophages in EAT (Figure 8A, 8C) and PAT (Figure 8B, 8D) both in ND and HFr groups compared to the ND-AIR control after the exposure of dirty air $(p<0.001)$. And the more significant macrophage infiltration was found in the HFr groups than in corresponding ND groups (Figure $8, p<0.05$ ). There was no additive 


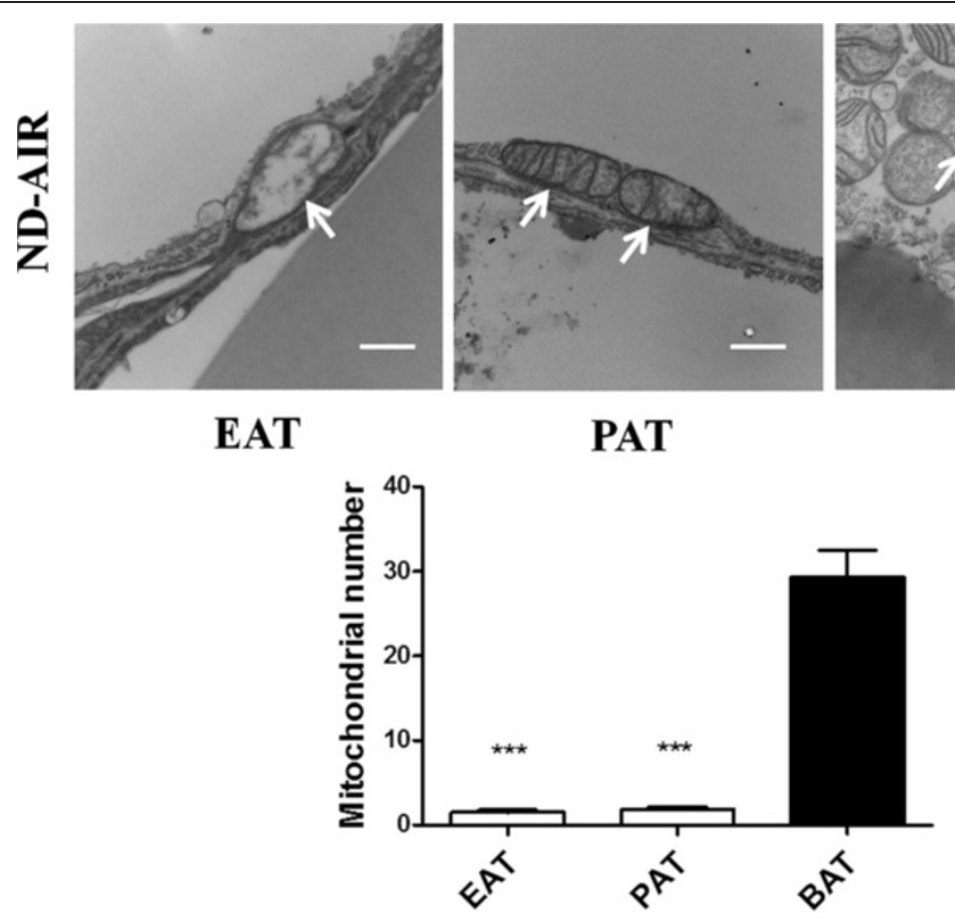

Figure 3 Mitochondrial numbers in different adipose tissues. Epicardial fat (EAT), perirenal fat (PAT) and interscapular fat (BAT) were from the rats fed a normal diet (ND) and exposed to the AIR by transmission electron microscopy (TEM). The arrows point to the mitochondria and the area of which was calculated from 6 images in each rat. Scale bars represent $500 \mathrm{~nm} .{ }^{* * *} p<0.001$ vs. BAT. $N=4$.

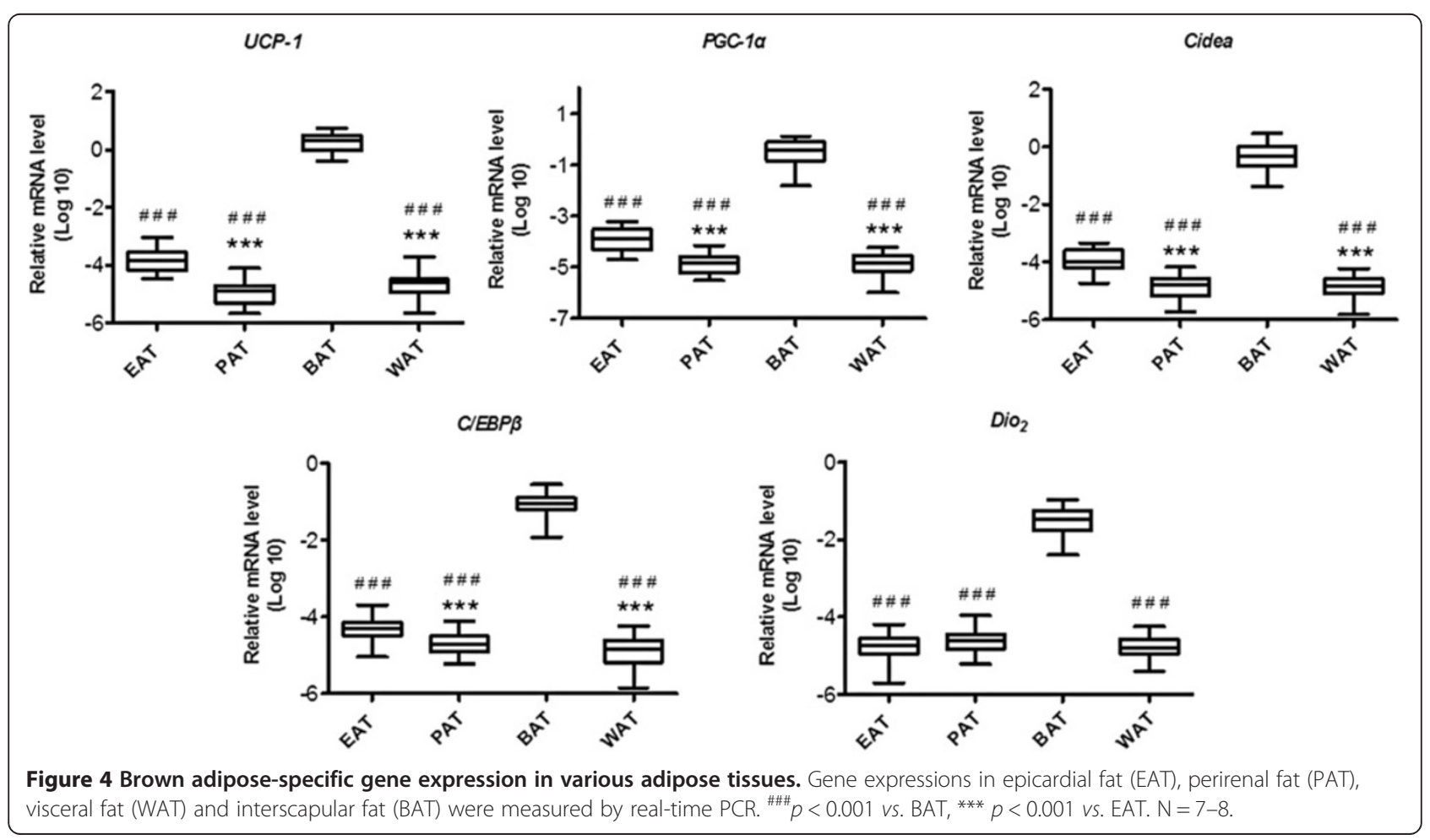




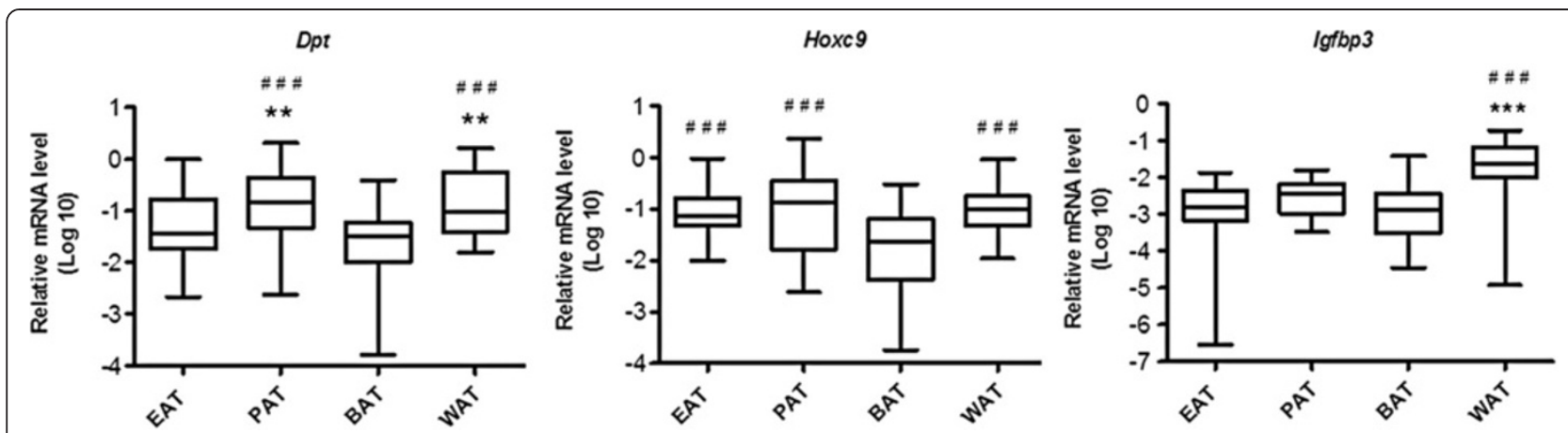

Figure 5 White adipose-specific gene expression in various adipose tissues. Gene expression in epicardial fat (EAT), perirenal fat (PAT), visceral fat (WAT) and interscapular fat (BAT) were measured by real-time PCR. ${ }^{* *} p<0.01,{ }^{* * *} p<0.001$ vs. EAT, ${ }^{\# \# \#} p<0.001$ vs. BAT. N $=7-8$.

increase of the CD68 staining in the group of co-exposure compared with that in the groups of single exposure to CAPs or $\mathrm{O}_{3}$ in EAT and PAT (Figure 8).

\section{Adipokine gene expression alteration}

To explore the inflammatory gene changes in response to the exposures, we examined the mRNA by quantitative real-time PCR. As shown in Figure 9, Tnf- $\alpha, M c p 1$ and leptin expressions were significantly up-regulated in response to the both co-exposure and single-exposure to CAPs and $\mathrm{O}_{3}$ in EAT (Figure 9A) and PAT (Figure 9B) in the HFr groups $(p<0.05)$, although no significant alteration was observed in the ND groups $(p>0.05$, Figure 9A, 9B) and no elevation in $I L-6$ gene expression was found in response to the exposures. Interestingly, the HFr-CAPs group demonstrated the highest $\operatorname{Tn} f-\alpha$, Mcp1 and leptin mRNA levels among all the groups (Figure 9A, 9B). Additionally, the mRNA levels of $I L-10$ and adiponectin in EAT (Figure 9A) and PAT (Figure 9B) were down-regulated in response to the CAPs and /or $\mathrm{O}_{3}$ exposures, especially in the HFr group, compared to the corresponding ND-groups (Figure 9, $p<0.05$ ). No significant increase of the inflammation response was found in the co-exposure of CAPs and $\mathrm{O}_{3}$ vs. single exposure to CAPs or $\mathrm{O}_{3}$ in EAT and PAT (Figure 9).

\section{iNOS expression}

Although nitric oxide (NO) plays an important role in various physiological processes, high concentration of NO may be cytotoxic, which can inhibit coronary artery function [10]. To evaluate whether iNOS contributed to the inflammation and oxidative stress in EAT and PAT, iNOS expression was determined by immunofluorescence. As shown in Figure 10, CAPs and/or $\mathrm{O}_{3}$ exposure resulted in increased iNOS immunofluorescence signal in EAT and PAT in HFr-CAPs, $\mathrm{HFr}-\mathrm{O}_{3}$ and HFr-CAPs +

Table 2 Characteristics of adipose tissues in the rats fed normal diet

\begin{tabular}{|c|c|c|c|c|}
\hline Item & EAT & PAT & WAT & BAT \\
\hline Color & white & white & white & brown \\
\hline Quantity & meager & less abundant & abundant & meager \\
\hline Vascular system & + & + & + & +++ \\
\hline Cell morphology & large unilocular cell & large unilocular cell & large unilocular cell & small multilocular cells \\
\hline nucleus & round and eccentric & round and eccentric & round and eccentric & flat and central \\
\hline Mitochondria number & meager & meager & meager & abundant \\
\hline Mitochondria cristae & meager & meager & meager & abundant \\
\hline$D p t$ & +++ & ++++ & ++++ & + \\
\hline Hoxc9 & +++ & ++++ & ++++ & + \\
\hline lgfbp3 & +++ & +++ & +++ & + \\
\hline UCP1 & ++ & + & + & ++++ \\
\hline$P G C-1 a$ & ++ & + & + & ++++ \\
\hline Dio2 & + & + & + & +++ \\
\hline$C / E B P \beta$ & + & + & + & +++ \\
\hline Cidea & ++ & + & + & +++ \\
\hline
\end{tabular}




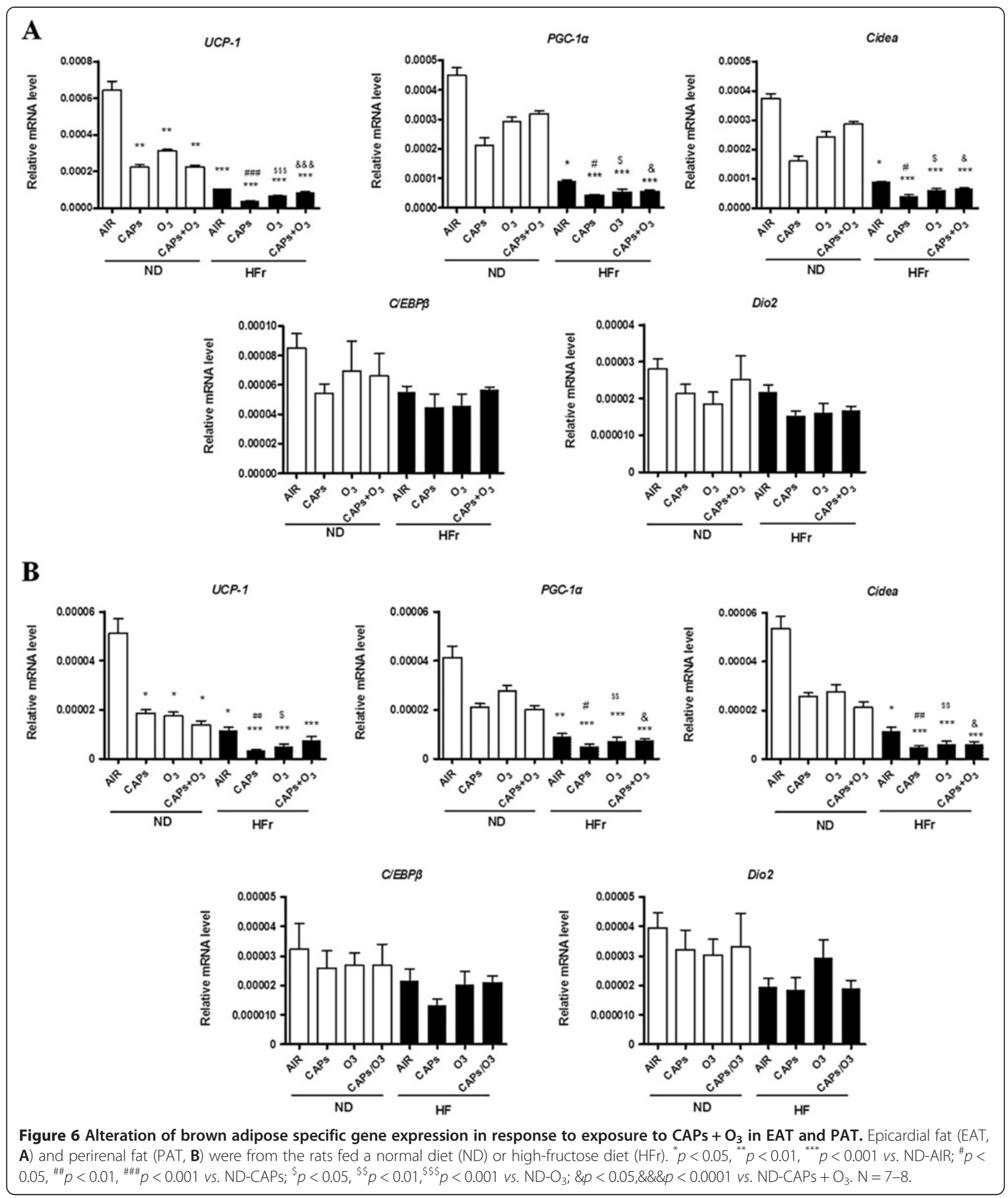

$\mathrm{O}_{3}$ compared to the ND-AIR groups $(p<0.05)$. Although the iNOS immunofluorescence revealed a two folds elevation in the HFr-AIR group over the ND-AIR group, it was not statistically significant $(p>0.05$, Figure 10C). Additionally, the strongest immunofluorescence signals were found in the HFr-CAPs groups rather than the coexposure ones although without significant differences $(p>0.05$, Figure 10). And significant increase of iNOS signals was observed in the HFr groups compared with the corresponding ND groups (Figure 10, $p<0.05$ ). As 


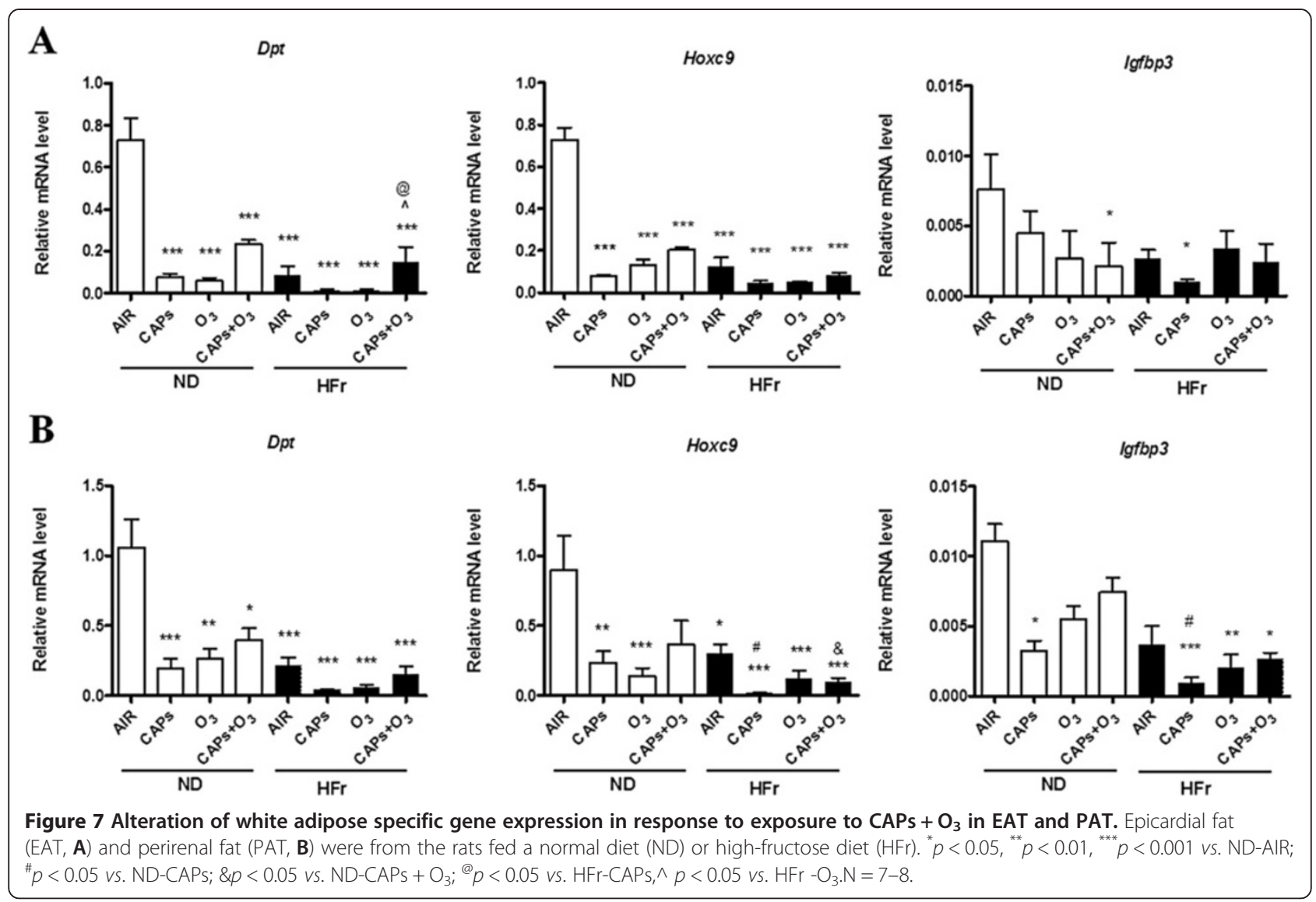

Table 3 Adiponectin concentrations in adipose tissues after the exposures

\begin{tabular}{|c|c|c|c|c|}
\hline \multirow{2}{*}{$\frac{\text { Adipose tissue }}{\text { EAT }}$} & \multirow{2}{*}{$\frac{\text { Diet \& exposure }}{\text { ND-AIR }}$} & \multicolumn{3}{|c|}{ Value, $\mathrm{ng} / \mathrm{mL}$} \\
\hline & & 55.54 & \pm & 3.57 \\
\hline & ND-CAPs & 58.38 & \pm & 0.36 \\
\hline & $\mathrm{ND}-\mathrm{O}_{3}$ & 56.00 & \pm & 0.85 \\
\hline & $\mathrm{ND}-\mathrm{CAPS}+\mathrm{O}_{3}$ & 67.32 & \pm & 0.75 \\
\hline & HFr-AIR & 56.40 & \pm & 1.66 \\
\hline & $\mathrm{HFr}$-CAPs & 62.10 & \pm & 0.93 \\
\hline & $\mathrm{HFr}-\mathrm{O}_{3}$ & 59.62 & \pm & 0.87 \\
\hline & $\mathrm{HFr}-\mathrm{CAPs}+\mathrm{O}_{3}$ & 55.81 & \pm & 1.69 \\
\hline \multirow[t]{8}{*}{ PAT } & ND-AIR & 43.64 & \pm & 1.31 \\
\hline & ND-CAPS & 44.66 & \pm & 0.96 \\
\hline & $\mathrm{ND}-\mathrm{O}_{3}$ & 44.70 & \pm & 1.02 \\
\hline & $\mathrm{ND}-\mathrm{CAPS}+\mathrm{O}_{3}$ & 45.69 & \pm & 0.70 \\
\hline & HFr-AIR & 45.81 & \pm & 1.22 \\
\hline & HFr-CAPs & 45.50 & \pm & 0.45 \\
\hline & $\mathrm{HFr}-\mathrm{O}_{3}$ & 40.66 & \pm & 3.05 \\
\hline & $\mathrm{HFr}-\mathrm{CAPs}+\mathrm{O}_{3}$ & 51.24 & \pm & 1.06 \\
\hline
\end{tabular}

Notes: $N D$ normal diet, AIR ambient air, CAPs concentrated ambient fine particulates, $\mathrm{O}_{3}$ ozone, $\mathrm{HFr}$ high-fructose diet, EAT epicardial adipose tissue, PAT perirenal adipose tissue, $\mathrm{N}=7-8$. shown in Figure 11, protein levels of iNOS were significantly elevated in the groups of HFr-CAPs and HFrCAPs $+\mathrm{O}_{3}$ compared to the ND-AIR groups in EAT as measured by Western blotting. In the ND-groups in EAT and all the eight groups in PAT, however, no significant increases were found on the levels of iNOS after the exposures to CAPs and/or $\mathrm{O}_{3} \quad(p>0.05$, Figure 11A-11D). Surprisingly, the highest protein levels were found in the co-exposure of CAPs and $\mathrm{O}_{3}$ vs. CAPs or $\mathrm{O}_{3}$ in EAT and PAT despite no significance difference $(p>0.05$, Figure 11).

\section{TEM in situ mitochondria alteration}

To explore if exposure to CAPs and $\mathrm{O}_{3}$ could induces mitochondria alteration in EAT and PAT, mitochondrial numbers and area were examined by TEM. Figure 12 showed representative TEM images of mitochondria in EAT (Figure 12A) and PAT (Figure 12B). Interestingly, the mitochondrial number in EAT and PAT had no significant change after the exposures $(p>0.05$, Figure 12C). However, mitochondrial area was significantly decreased in the groups of HFr-CAPs, $\mathrm{HFr}-\mathrm{O}_{3}$ or $\mathrm{HFr}-\mathrm{CAPs}+\mathrm{O}_{3}$ compared to the ND-AIR group in both EAT and PAT $(p<0.05$, Figure 12D), although the decrease was not significant in the ND fed groups ( $p>0.05$, Figure 12D). 


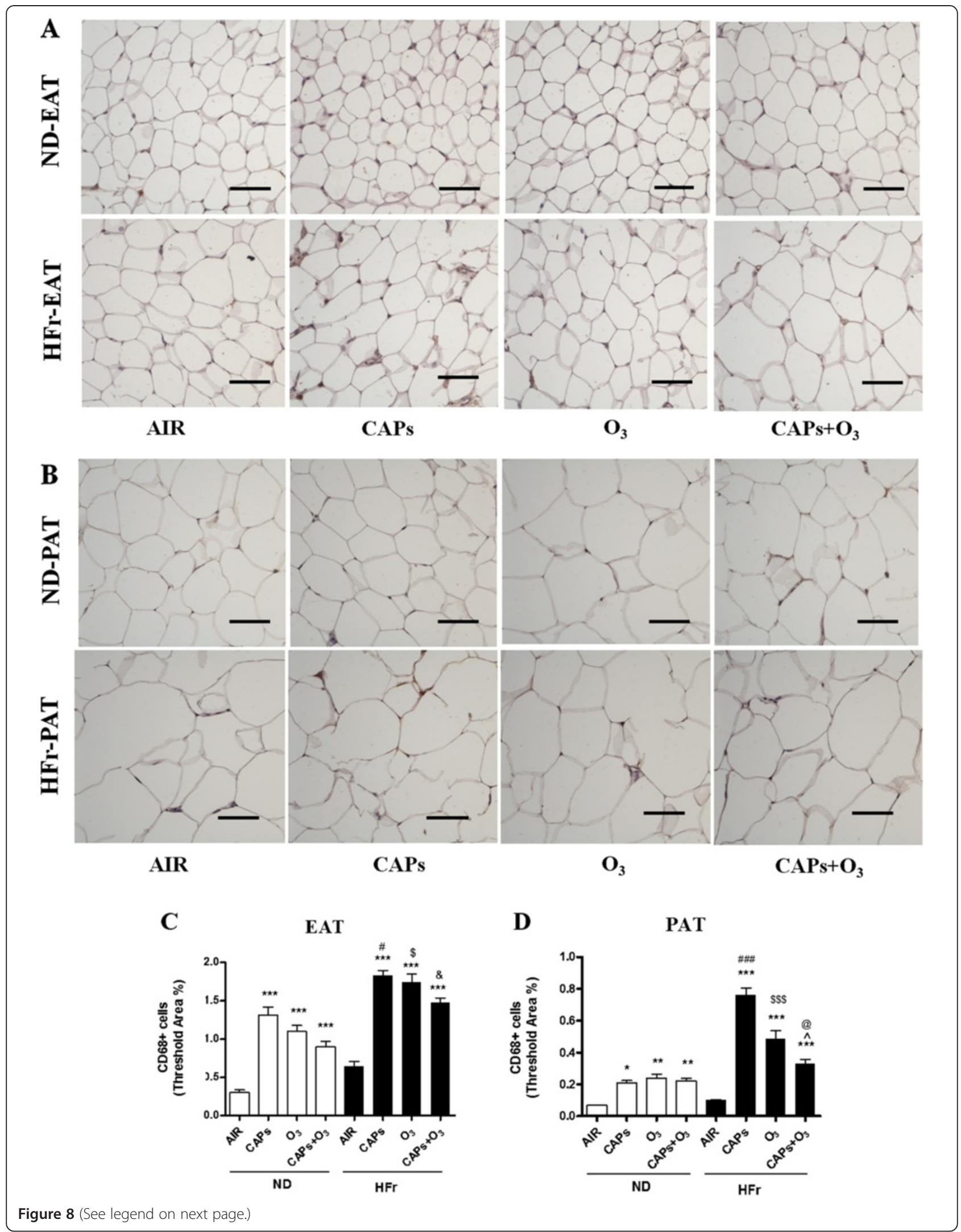


(See figure on previous page.)

Figure 8 Macrophage infiltration in response to CAPs and $\mathbf{O}_{3}$ exposures in EAT and PAT. A and $\mathbf{B}$, Representative images of

immunohistochemical staining for CD68 in EAT (A) and PAT (B). C and D, Threshold area analyses of macrophages in EAT (C) and PAT (D). * $p<$ $0.05,{ }^{* *} p<0.01,{ }^{* * *} p<0.001$ vs. ND-AIR; ${ }^{\#} p<0.05,{ }^{\# \# \#} p<0.001$ vs. ND-CAPs; ${ }^{\$} p<0.05,{ }^{\$ \$} p<0.001$ vs. ND-O $; ; \& p<0.05$ vs. ND-CAPs $+\mathrm{O}_{3} ;{ }^{@} p<0.05$ vs. HFr-CAPs, $\wedge p<0.05$ vs. HFr $-\mathrm{O}_{3}$. Scale bars represent $100 \mu \mathrm{m} . \mathrm{N}=7-8$.

\section{Bronchoalveolar lavage cellularity}

Exposure to $\mathrm{O}_{3}$ elicited a significant increase in macrophages in bronchoalveolar fluid in $\mathrm{HFr}_{-} \mathrm{O}_{3}$ rats (Figure 13B). In comparison, changes in concentrations of total cells, neutrophils or lymphocytes were not statistically significant (Figure 13A, 13C and 13D).

\section{Discussion}

In this study, we investigated the morphological characteristics of various adipose tissues, which include EAT, PAT, WAT and BAT, and assessed the effects of inhalational exposures to CAPs and $\mathrm{O}_{3}$ on WAT and BAT specific gene expressions, as well as alterations in inflammatory gene expression in EAT and PAT in response to high-fructose feeding. To the best of our knowledge, this was the first study to evaluate the WAT and BAT specific gene alteration, especially systemic inflammatory and oxidative stress response to CAPs and $\mathrm{O}_{3}$ exposures in EAT and PAT in rats. Our current study showed that HFr feeding led to adipocytes hypertrophy in EAT, PAT, and WAT. EAT volume has been shown to strongly and independently reflect the fat volume of perirenal and omental visceral fat tissues lipid depots $[11,12]$, which seems to be important in systemic inflammation [13], insulin resistance and metabolic syndrome [14]. As to the typical WAT and BAT, we have previously demonstrated the oxidative stress and changes of mitochondria and genes expression in response to the exposure of ambient fine particulates [1]. Therefore, we mainly focused on the inflammation and oxidative stress especially in EAT and PAT in the present study. We demonstrated that EAT and PAT were broadly resembling WAT based on morphology, and overall mitochondrial numbers and gene expression. Notwithstanding, EAT differed in many respects from typical WAT. Both EAT and PAT had less mitochondria than typical BAT and higher expression of WAT specific genes ( $D p t$ and Hoxc9) while lower BAT specific gene profiles (Ucp-1, $P g c-1 \alpha$ and Cidea), which were approximately 1,000 folds lower than in BAT $[15,16]$. Interestingly, EAT was quite different from other WAT depots, with much smaller adipocytes [17] and higher mRNA levels of Ucp1, Pgc-1 $\alpha$ and Cidea expressions than PAT and WAT. These findings may suggest an unique role of EAT. EAT has been suggested to play a role in a variety of processes relating to preservation of myocardial form and function. For instance, it may play an athermogenic function and protect against significant excursion in temperature and protect against arrhythmias [3,18]. EAT is now recognized as a rich source of free fatty acids, a key of energy for the heart, and has been suggested to secrete a number of bioactive molecules [19,20]. Additionally, EAT also has storage function. Higher levels of both lipolysis and lipogenesis than other adipose depots confer "dual capability" of accumulating lipids for storage and also releasing them rapidly in response to demand. The latter function may explain high expressions of Ucp-1, Pgc-1 $\alpha$ and Cidea in EAT [21].

We also found that short-term inhalational exposure to CAPs and $\mathrm{O}_{3}$ significantly downregulated WATspecific genes (Hoxc9 and Dpt) and BAT-specific genes (Ucp-1, Pgc-1 $\alpha$ and Cidea) in EAT and PAT. Hoxc9 belongs to the homeobox family of genes, and it is recognized as WAT specific marker in primary adipocyte cultures [22]. Overall, an important observation was that co-exposure to CAPs and $\mathrm{O}_{3}$ did not appear to potentiate co-effects with most of these genes, while HFr plus CAPs exposure was often the strongest factors pertaining to inflammation in adipose tissues. In some instances, co-exposure to CAPs and $\mathrm{O}_{3}$ led to less pronounced (albeit some are non-significant) inflammation in EAT and PAT than the single component exposure to CAPs or $\mathrm{O}_{3}$. Dpt is regarded as a marker for white adipogenesis and as a reference gene for the "whitening" phenomenon [1,23]. Ucp-1 uncouples substrate oxidation and electron transport through respiratory chains from adenosine triphosphate production that results in dissipation of energy as heat and thereby playing a pivotal role in thermogenesis and protecting against reactive oxygen species (ROS) [24]. This is caused by an increased proton leakage over the inner mitochondrial membrane which dissipates the proton motive force as heat instead of adenosine triphosphate synthesis [25]. $P g c-1 \alpha$, also a marker for BAT, induces mitochondrial biogenesis and thermogenesis [26]. The cell deathinducing DNA fragmentation factor- $\alpha$-like effector (Cidea) family plays important roles in lipid droplet formation, and is critically involved inlipogenesisand lipolytic metabolism [27]. The downregulation of Ucp-1,Pgc-1 $\alpha$ and Cidea in response to CAPs and $\mathrm{O}_{3}$ suggests an important effect of exposure in modulating thermogenic functions and lipogenesis pathways. In this current study, we did not find significant expression alteration of Dio2 and $C / e b p \beta$ (BAT specific genes) [28] and Igfbp3 (WAT specific gene) [29] in EAT and PAT after the exposures of CAPs and $\mathrm{O}_{3}$. Additionally, we found there 


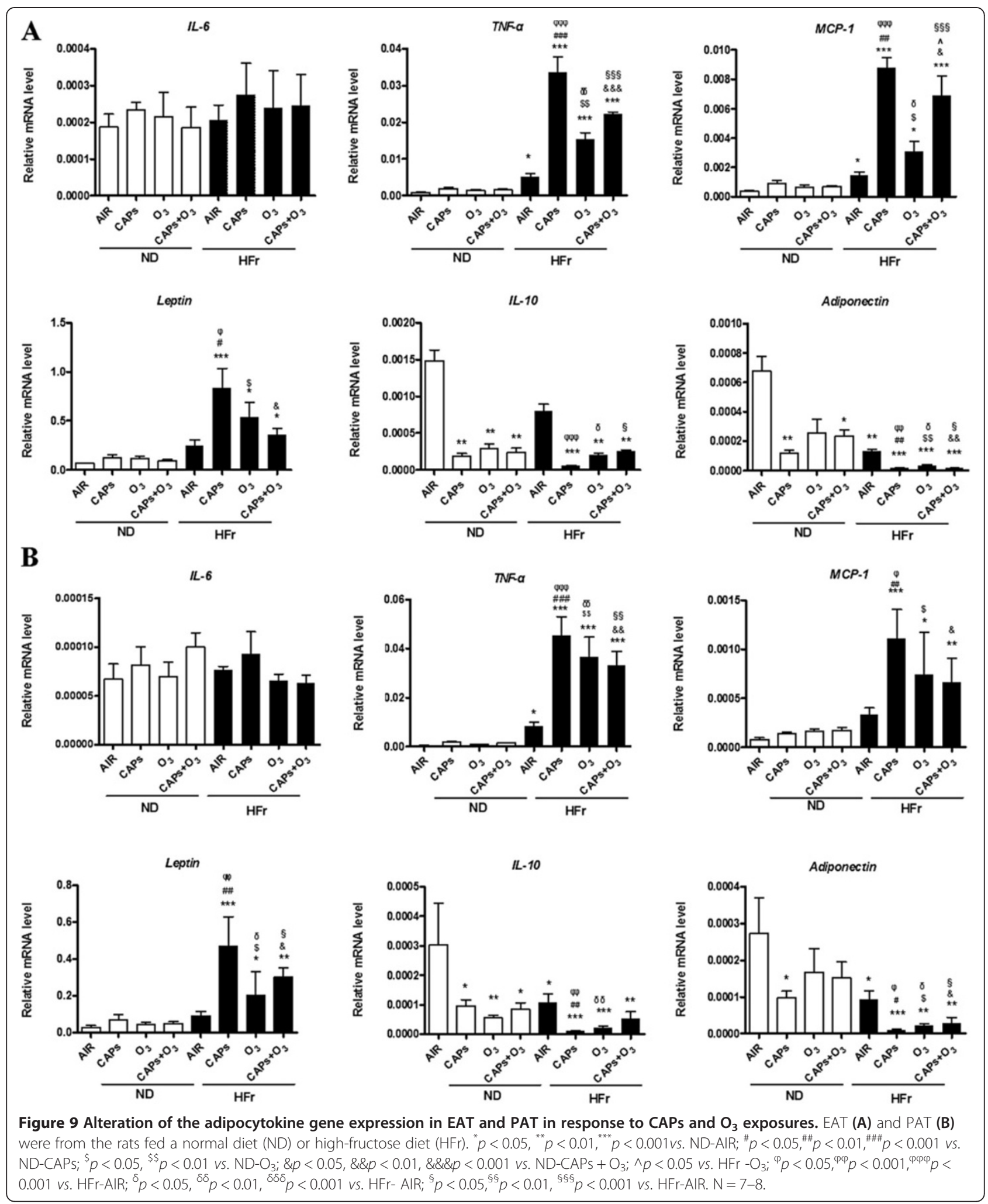

were significantly synergistic interactions of high fructose and dirty air exposure on most of the WAT and BAT specific genes regulation in the present study.
A striking finding of this study was the relatively modest effects of HFr alone on inflammatory effects in EAT and PAT. In contrast, CAPs plus the HFr diet was 


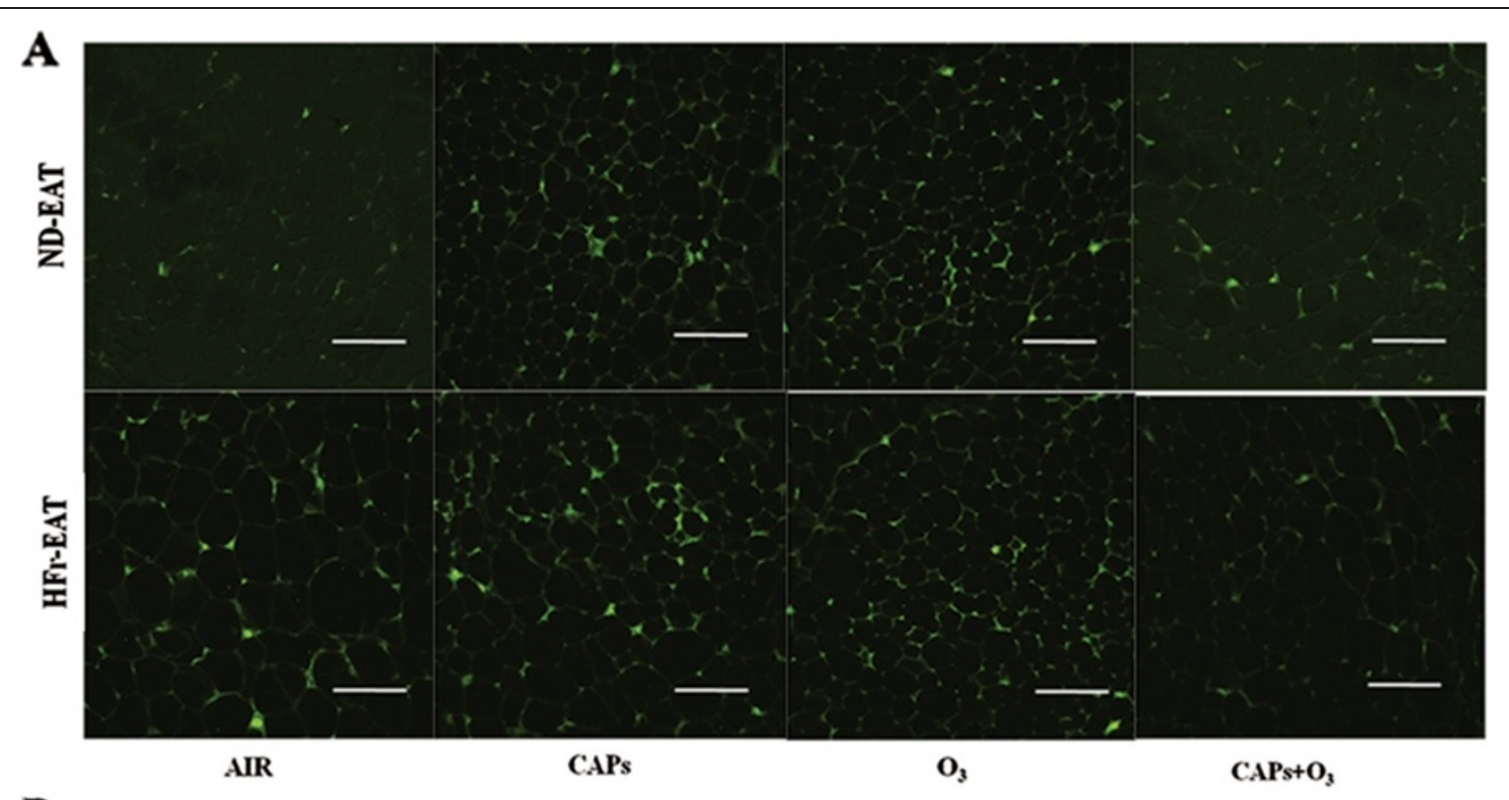

B

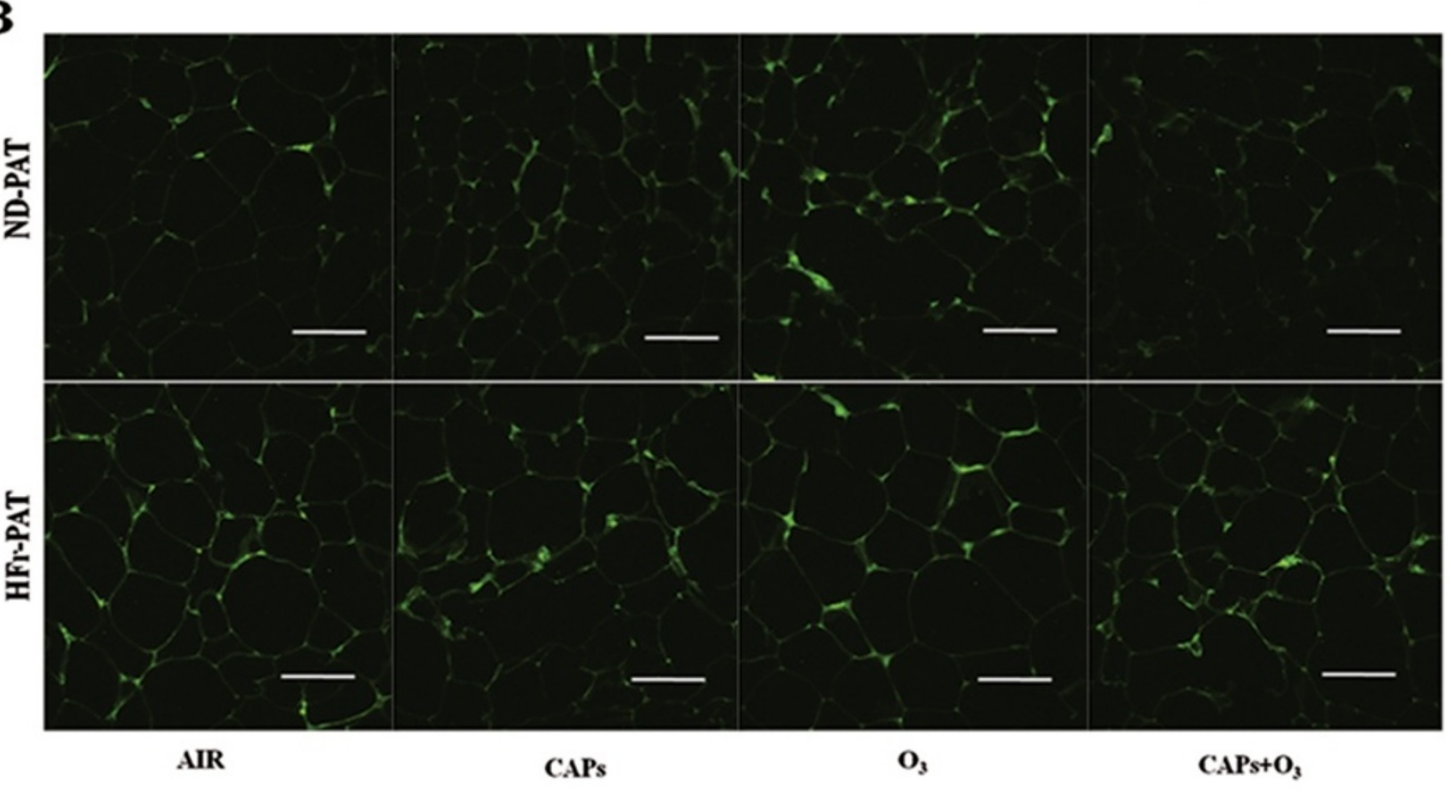

C

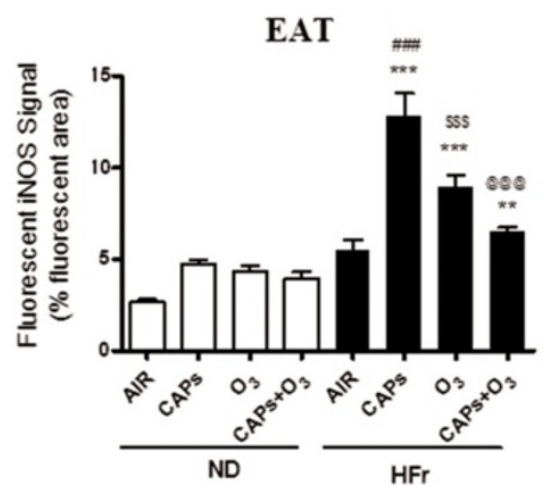

D

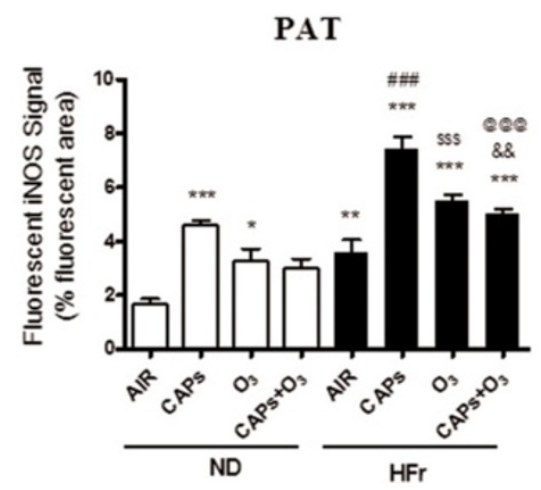

Figure 10 (See legend on next page.) 
(See figure on previous page.)

Figure 10 Alteration of iNOS immunofluorescent signals in EAT and PAT in response to CAPs and $\mathrm{O}_{3}$ exposure. A and $\mathrm{B}$, Representative iNOS immunofluorescent staining photomicrographs of EAT (A) and PAT (B). $\mathbf{C}$ and $\mathbf{D}$, iNOS staining signals were quantified by the percentage of green immunofluorescence areas in 5 random fields per section in EAT (C) and PAT (D). ${ }^{*} p<0.05,{ }^{* *} p<0.01,{ }^{* * *} p<0.001$ vs. ND-AIR; ${ }^{\# \# \#} p<0.001$ vs. ND-CAPs; ${ }^{\$ \$} p<0.001$ vs. ND-O $;$; \& $\$ p<0.01$ vs. ND-CAPs $+\mathrm{O}_{3} ;{ }^{@ @ @ ~} p<0.001$ vs. HFr-CAPs. $N=4$.

sufficient to potentiate inflammatory responses both in EAT and PAT. It did appear to be a significantly additive or synergistic effect of both high fructose and dirty air exposure on most inflammatory genes (albeit some are non-significant). Pro-inflammatory adipokines, such as Mcp-1, Tnf- $\alpha$, and Leptin, were found to be generally upregulated with the levels being highest in response to CAPs exposure alone, while anti-inflammatory adipokines, such as $I L-10$ and Adiponectin, were downregulated in response to the exposures in the HFr-group rats in this study. These results suggest that CAPs and $\mathrm{O}_{3}$ exposures may result in a pro-inflammatory macrophages shift in EAT and PAT. Interestingly, $I L-6$, also regarded as a pro-inflammatory adipokine, was not changed in gene expression in response to the dirty air exposures in this study. This was consistent with the function of $I L-6$, which was an acute-phase responsive cytokine and might be expressed at an earlier time point [30]. Surprisingly, almost no significant increases of the inflammation and oxidative stress responses were found in the co-exposure of CAPs plus $\mathrm{O}_{3}$ vs. CAPs or $\mathrm{O}_{3}$ single exposure in EAT and PAT, except the iNOS protein level, which seemed to have a ceiling effect. Another possibility could be that the $\mathrm{O}_{3}$ concentrations used in this project was relatively low and it was metabolized quickly and possibly locally in the upper respiratory track that might not have substantial systemic impact [31]. The discrepancy in iNOS expression between fluorescence assay and Western blot was likely due to the different sensitivity and different binding targets of those two methods [32]. We also found significant increases only in macrophages of $\mathrm{HFr}-\mathrm{O}_{3}$ rats. This response in $\mathrm{HFr}-\mathrm{O}_{3}$ rats was associated with mild para-acinar accumulation of macrophages, but histological responses were otherwise unremarkable (pathology not shown). By comparison, airway neutrophils, lymphocytes and eosinophils were unaffected by exposures or diet. Therefore, airway inflammation was not associated with the adipose

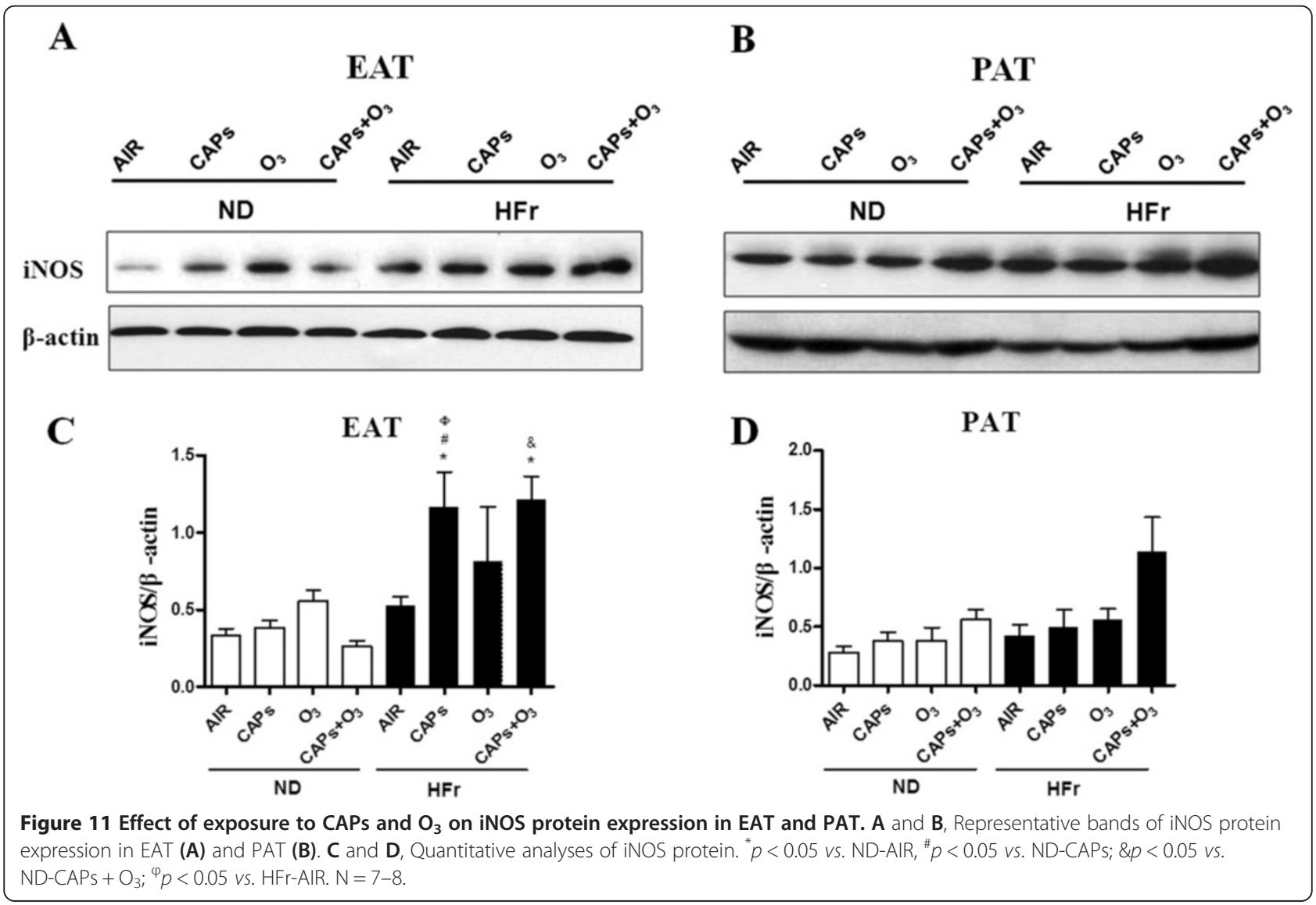



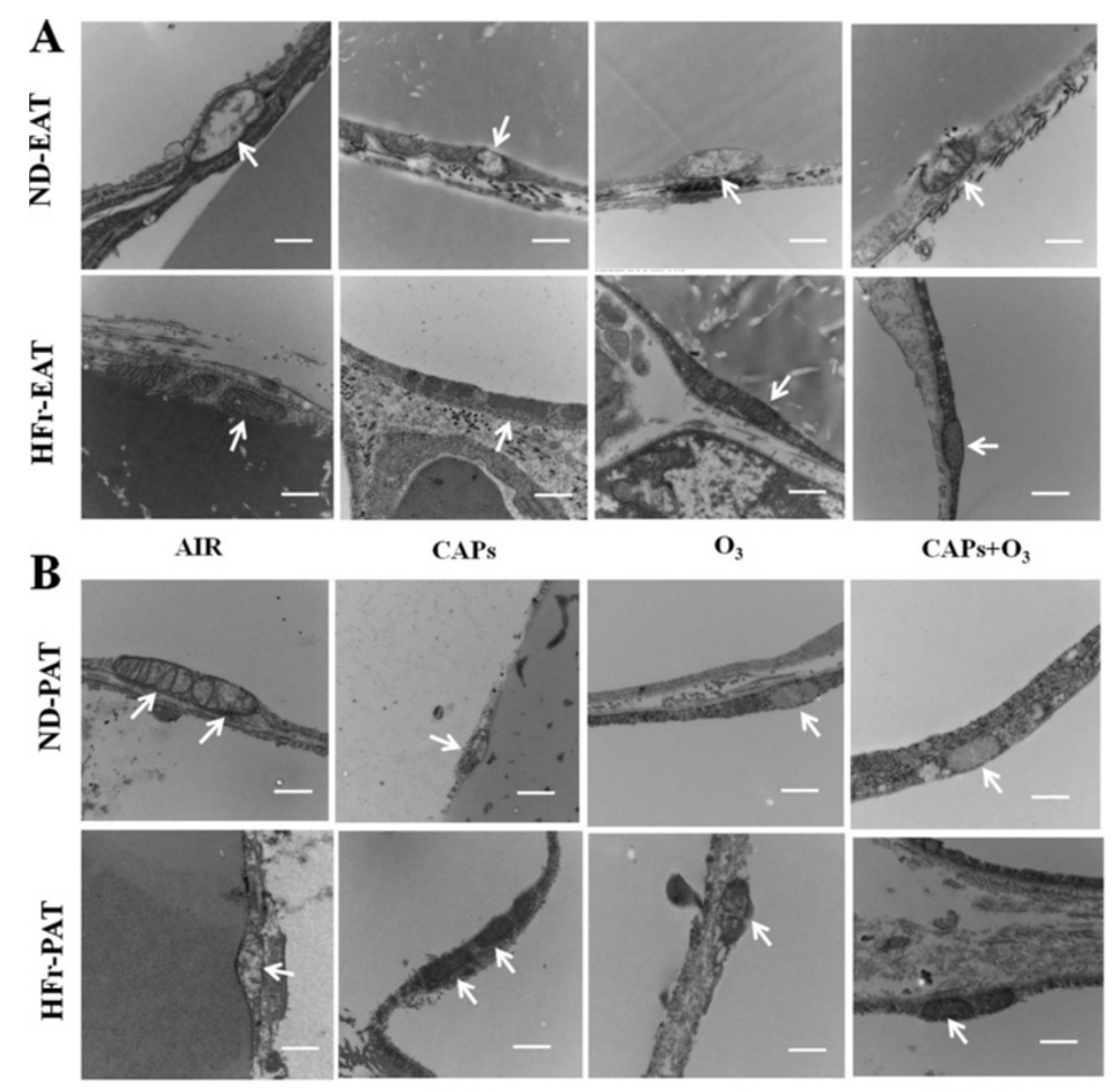

AIR

$\mathbf{O}_{3}$

$\mathrm{CAPs}+\mathrm{O}_{3}$

C

EAT
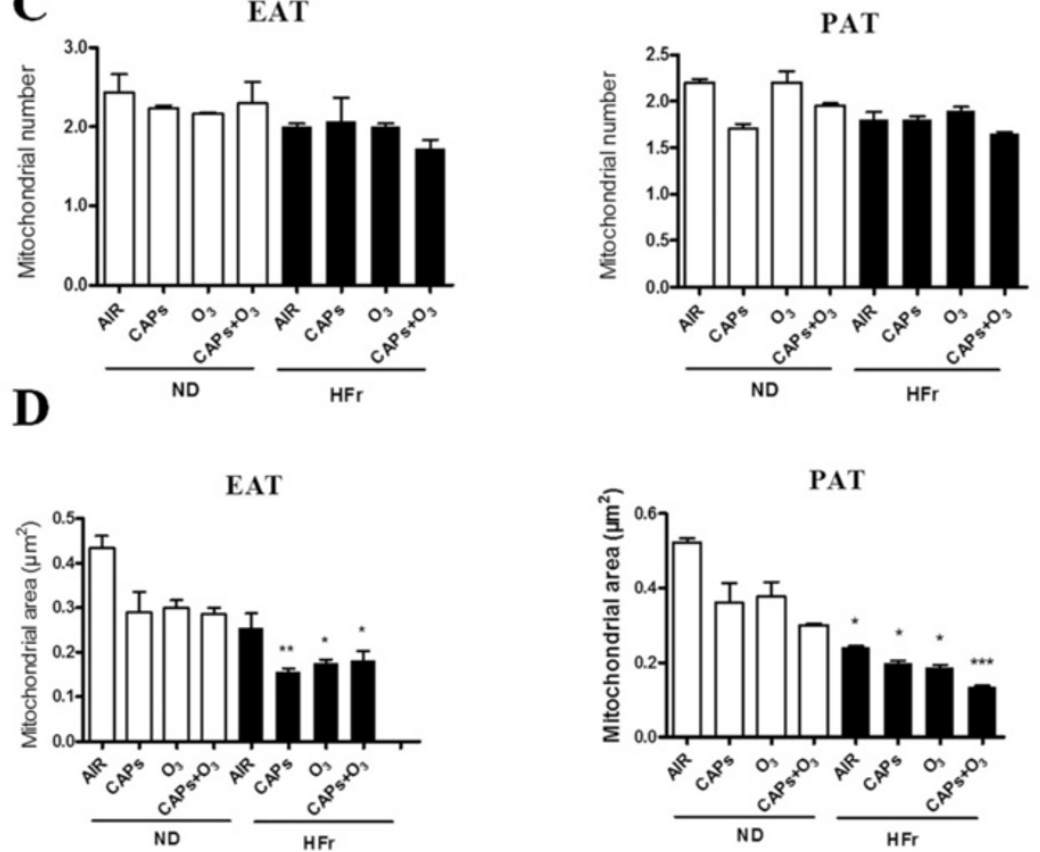

Figure 12 Mitochondrial alteration in EAT and PAT by TEM in response to CAPs and $\mathrm{O}_{3}$ exposure. A and $\mathrm{B}$, Representative TEM photomicrographs of EAT (A) and PAT (B). C and $\mathbf{D}$, The analyses of mitochondrial number and area in EAT(C) and PAT(D). Scale bars represent $500 \mathrm{~nm}$. Arrows point to mitochondria. $p<0.05,{ }^{* * *} p<0.01,{ }^{* * *} p<0.001$ vs. ND-AIR. N $=4$. 

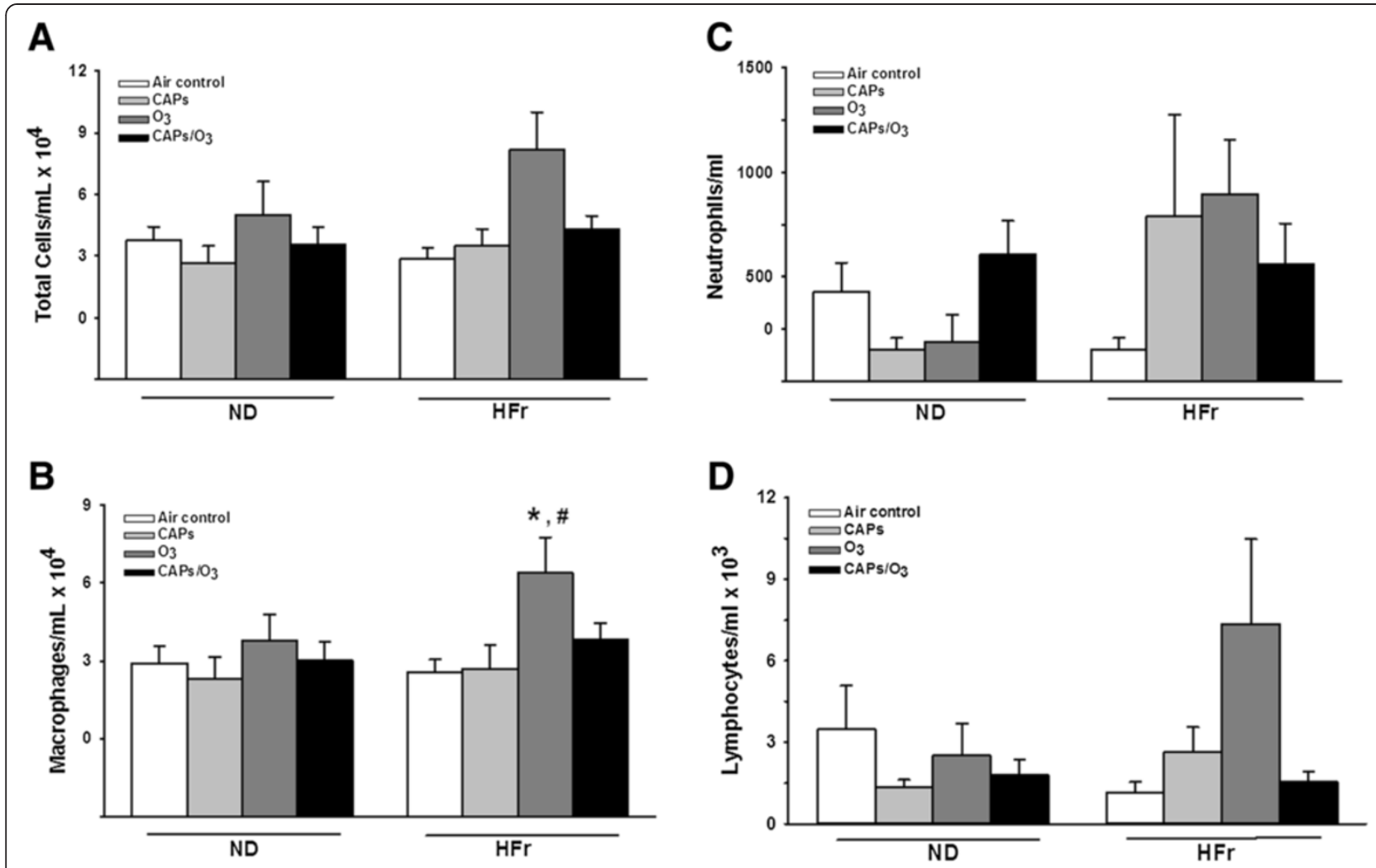

Figure 13 Bronchoalveolar lavage cellularity. Bronchoalveolar fluid contents of total cells (A), macrophages (B), neutrophils (C), and lymphocytes (D) were determined in cytospin samples from rats exposed to $\mathrm{O}_{3}$, CAPs or CAPs $+\mathrm{O}_{3}$ as described in methods. * indicates significant difference from similarly expose ND rats; "indicates significant difference from AlR exposed HFr rats. $N=4$.

responses we described. The synergetic interaction of HFr and dirty air exposure on the inflammation was found in most of the experiments. The attenuation of $\mathrm{CAP}_{\mathrm{S}}$ effect with $\mathrm{O}_{3}$ has been reported in combined exposure studies previously $[33,34]$. In a rat model exposed to $\mathrm{O}_{3}$ and diesel exhaust particles, the combined exposures of $\mathrm{O}_{3}$ and diesel exhaust particles had less pronounced effects, which showed elevated biomarkers of oxidative stress (hemeoxygenase-1), thrombosis (tissue factor, plasminogen activator inhibitor-1, tissue plasminogen activator, and von Willebrand factor), vasoconstriction pertaining to vascular impairments in the aorta, with the loss of phospholipid fatty acids in myocardial mitochondria, than exposure to either pollutant alone [34]. In another study with rats exposed to ambient particulate matter, $\mathrm{O}_{3}$, or combinations for 4 hours, both pollutants transiently increased endothelin-B receptor mRNA expression, while $\mathrm{O}_{3}$ decreased endothelin-A receptor mRNA levels. Pollutants and $\mathrm{O}_{3}$ have been hypothesized to attenuate their effects by virtue of chemical reaction or chemical modification in the ambient air prior to interacting with biological molecules inside the body [35]. However, the credible mechanisms of inhalational CAPs plus $\mathrm{O}_{3}$ coexposure resulting in less conspicuous effects compared with single exposure, still are lacking but remain an area of intense research in the field of exposure toxicology.

In the current study using the Harvard-type fine particle we generated CAPs concentrations of of $300-400 \mu \mathrm{g} / \mathrm{m}^{3}$ that very high can occur near point sources of pollution (e. g. traffic), in major industrial cities in north American, or some regions in developing countries like China. Such exposures are usually episodic, unlike our current protocol of nine continuous weekdays. However in a recent CAPs study in mice where exposures were conducted longer (2 months) and to lower $\mathrm{PM}_{2.5}$ concentrations $\left(98 \mu \mathrm{g} / \mathrm{m}^{3}\right)$, we described similar adipose responses in mitochondria number and size, Ucp1 expression, and BAT and WATspecific gene expression [1], as we describe in the current study. Furthermore the total mass of exposures $(c \times t)$ between the two exposures is quite similar (26-28 mg). Thus it is possible that different pathways were initiated in each study, but they both appear to converge to induce the same adipose responses. The key finding is that exposures in the current study failed to elicit responses in healthy rats, while adipose responses only occurred in fructose-fed rats.

What are the implications of this study for myocardial and coronary disease and renal function? A limitation of this study is the lack of functional characterization in 
response to changes in EAT and PAT with HFr diet and exposures. Thus one can only speculate on the potential implications of this study. The possible transmural movement of macrophages from EAT into the adjacent coronary artery walls has been speculated as being involved in atherogenesis and acute coronary syndromes [36]. Indeed, substantial macrophages infiltration in coronary artery vulnerable plaques has been described in EAT that was obtained during cardiac surgery of patients with severe coronary artery stenosis [37]. The upregulation of $M c p-1$ and $T n f-\alpha$, which are prototypical chemokine and inflammatory triggers, extensively implicated in multiple steps of inflammation and propensity for complications in Type II DM and coronary atherosclerosis.

In summary, our study demonstrates the rapid inflammation in EAT and PAT in response to environmental exposure to inhalational toxins plus high fructose diet. Our findings may provide a link between air-pollution exposure and accelerated susceptibility to cardiovascular diseases and metabolic complications, especially for multiple synergistic risk factors.

\section{Conclusions}

HFr feeding led to hypertrophy of adipocytes in EAT, PAT, and WAT. Short-term exposure to CAPs and $\mathrm{O}_{3}$, especially the single exposure to CAPs, induced inflammation and oxidative stress in EAT and PAT in rats. These findings suggest that inflammation and oxidative stress in adipose tissues may be one of the important mechanisms of air pollution exposure-induced cardiovascular diseases.

\section{Methods}

\section{Animals}

Eight-week-old male Sprague-Dawley rats (250-275 g) were purchased from Charles River Laboratories (Portage, $\mathrm{MI})$. The rats were fed either a normal diet (ND) or highfructose diet (HFr; 60\% fructose by mass; TD.89247; Harlan Laboratories, Madison, WI). Rats fed a HFr diet for 6-8 weeks develop hypertension and insulin resistance, and therefore have been used to model metabolic syndrome in humans as detailed previously $[38,39]$. After 8 weeks on ND or HFr diets, rats were exposed to AIR, CAPs, $\mathrm{O}_{3}$, or CAPs $+\mathrm{O}_{3}$, for a total of 8 experimental groups: ND-AIR, ND-CAPs, ND-O $3, \quad \mathrm{ND}-\mathrm{CAPs}+\mathrm{O}_{3}$, HFr-AIR, HFr-CAPs, HFr- $\mathrm{O}_{3}$, and HFr-CAPs $+\mathrm{O}_{3}(\mathrm{n}=$ 7-8 per group). Inhalation exposures were conducted 8 h/day for 9 days over 2 weeks (Mon-Fri; Mon-Thu). All rats were sacrificed $24 \mathrm{~h}$ after the last exposure in a laboratory at Michigan State University (MSU) in East Lansing, MI. This investigation conformed to the Guide for the Care and Use of Laboratory Animals by the US National Institutes of Health (NIH Publication No. 85-23, revised 1996), and the study protocols were approved by the Institutional Animal Care and Use Committee of MSU, an AAALAC accredited institution.

\section{Exposures and tissue collection}

Inhalation exposures by whole-body were conducted in AirCARE 1, a mobile air research laboratory temporarily located in the parking lot of Salinas Elementary School in Dearborn, MI during the summer of 2011. This location is a stationary air pollution monitoring site run by the Michigan Department of Environmental Quality. This site continues to have some of the highest annual airborne concentrations of $\mathrm{PM}_{2.5}$ in the state of Michigan, and is located within $5 \mathrm{~km}$ of iron/steel production facilities, a coke oven, oil refinery, sewage sludge waste incinerator, and a coal-fired power plant. Thus, the $\mathrm{PM}_{2.5}$ at this site is impacted by multiple industrial pollutant emission point sources [9].

CAPs were generated from ambient $\mathrm{PM}_{2.5}$ using a Harvard-type fine particle concentrator and whole body animal exposures were conducted in Hinners chambers. The specific details of the concentrator performance and the inhalation exposure systems within AirCARE 1 have been described previously [40,41]. $\mathrm{O}_{3}$ was generated using an $\mathrm{ORECO}_{3}$ generator (Model V1; uv method), and $\mathrm{O}_{3}$ concentration was targeted at $0.05 \mathrm{ppm}$ during all exposure scenarios. Due to space constraints in the exposure chambers, exposure to CAPs $+\mathrm{O}_{3}$ or AIR was run at different weeks (July 25 - Aug 4) as exposure to CAPs or $\mathrm{O}_{3}$ alone (Aug 15-25). All of the rats were sacrificed within the $24 \mathrm{~h}$ after exposure (Aug 5 and Aug 26), and WAT (visceral fat- omental adipose tissue), BAT (interscapular adipose tissue), EAT and PAT were harvested and stored, respectively. In addition, the trachea was exposed and cannulated, and the heart and lung were excised en bloc. The bronchus to the left lung was temporarily closed with a hemostatic clamp, and $5 \mathrm{ml}$ of sterile saline was instilled through the tracheal cannula and withdrawn to recover bronchoalveolar lavage fluid from the right lung lobes. A second saline lavage was performed and combined with the first.

\section{Characterization of CAPs}

CAPs mass concentrations were determined using a microbalance (MT-5 Mettler Toledo, Columbus OH) in a temperature/humidity-controlled Class 100 clean laboratory. PM samples collected on quartz filters were analyzed for carbonaceous aerosols by a thermal-optical analyzer using the NIOSH method (Sunset Labs, Forest Grove, OR). The speciation of organic and elemental carbon (OC and EC, respectively) was accomplished through gradient heating and continuous monitoring of filter transmittance with flame ionization detection. Annual denuder/filter pack samples were analyzed for major 
ions such as sulfates, nitrates and ammonium by ion chromatography (Model DX-600, DIONEX, Sunnyvale, CA). Furthermore, PM samples collected on Teflon filters were wetted with ethanol and extracted in $1 \%$ nitric acid solution. Sample extracts were then analyzed for a suite of trace elements using inductively coupled plasma-mass spectrometry (ICP-MS) (ELEMENT2, Thermo Finnigan, San Jose, CA) as detailed previously [38]. To estimate the contribution of urban dust in southwest Michigan, we used the equation $1.89^{*} \mathrm{Al}+1.4 * \mathrm{Ca}+1.43^{*} \mathrm{Fe}+2.14^{*} \mathrm{Si}$, where $\mathrm{Si}$ is estimated by $\mathrm{K} / 0.15$ [42].

\section{Enzyme-linked immunosorbent assay (ELISA)}

EAT and PAT tissues ( $\sim 50 \mathrm{mg}$ wet weight) were incised into small pieces and immersed into $0.6 \mathrm{~mL}$ cell culture media, respectively, then incubated at $37^{\circ} \mathrm{C}$ overnight. The supernatant of the media was collected separately and stored at $-80^{\circ} \mathrm{C}$ for the analysis of adiponectin. The adiponectin levels were determined using an adiponectin quantification kit (ELISA Kit, AdipoGen, San Diego, CA) following the manufacturer's instructions.

\section{Quantitative real-time polymerase chain reaction (PCR)}

Total RNA was extracted with Trizol reagent (Invitrogen, Grand Island, NY) from EAT, PAT, WAT and BAT according to the manufacturer's instructions. Total RNA was then converted into cDNA using a High Capacity cDNA Reverse Transcription Kit (Applied Biosystems, Foster City, CA). The quantification of gene expression was determined by real-time PCR. All reactions were performed under the same condition: $50^{\circ} \mathrm{C}$ for $2 \mathrm{~min}$, $95^{\circ} \mathrm{C}$ for $10 \mathrm{~min}, 40$ cycles of $95^{\circ} \mathrm{C}$ for $15 \mathrm{~s}$, and $60^{\circ} \mathrm{C}$ for $1 \mathrm{~min}$. The primers for rat uncoupling protein 1 $(U c p-1)$, peroxisome proliferative activated receptor, gamma, coactivator 1 alpha $(P g c-1 \alpha)$, type 2 iodothyronine deiondinase (Dio2), CCAAT enhancing binding protein $\beta(C / e b p \beta)$, cell death-inducing DNA fragmentation factor-like effector A (Cidea), dermatopontin (Dpt), homeobox C9 (Hoxc9), insulin-like growth factor binding protein 3 (Igfbp3), leptin, tumor necrosis factor- $\alpha(\operatorname{Tn} f-\alpha)$, monocyte chemotactic protein-1(Mcp-1), interleukin $(I L)$ 6, Adiponectin, $I L-10$, and $\beta$-actin were shown in Table 4. $\beta$-actin was used as the house-keeping gene, and all data were presented as relative mRNA levels.

\section{Western blotting}

EAT, PAT, WAT, and BAT were homogenized in M-PER mammalian protein extraction reagent (Thermo Fisher Scientific, Waltham, MA), incubated on ice for $30 \mathrm{~min}$, followed by centrifugation at $12,000 \mathrm{~g}$ for $10 \mathrm{~min}$ at $4^{\circ} \mathrm{C}$. The supernatants were collected and subjected to Western blotting analysis. Protein concentrations were determined by BCA assay (Bio-Rad Laboratories, Hercules, CA). Twenty micrograms of protein was separated by $6 \%$ SDS polyacrylamide gel electrophoresis and subsequently transferred to polyvinylidene difluoride membrane. After blotting in 5\% non-fat dry milk in PBS -Tween 20, the membranes were incubated with primary antibody against iNOS (Santa Cruz Biotechnology, Santa Cruz, CA) at 1:1000 dilution, followed by treatment with rabbit antimouse IgG-HRP antibody (Santa Cruz Biotechnology) at 1:1000 dilution. The membranes were detected with

Table 4 Primers used for real-time PCR

\begin{tabular}{|c|c|c|c|}
\hline Gene & Forward oligonucleotides $\left(5^{\prime}-3^{\prime}\right)$ & Reverse oligonucleotides $\left(5^{\prime}-3^{\prime}\right)$ & Product size (bp) \\
\hline$U c p-1$ & TCAACACTGTGGAAAGGGACGACT & TCTGCCAGTATGTGGTGGTTCACA & 119 \\
\hline Pgc-1a & ACGAAAGGCTCAAGAGGGACGAAT & CACGGCGCTCTTCAATTGCTTTCT & 108 \\
\hline Dio2 & TGAGGTTAAGAAGCACCGGAACCA & CGTTGGCATTATTGTCCATGCGGT & 122 \\
\hline Clebp $\beta$ & TGATGCAATCCGGATCAAACGTGG & TTAAAGTGATTACTCAGGGCCCGGCT & 97 \\
\hline Cidea & ACCATCTGTTACAGGCTGTGGGAT & AAAGCTCTTGAAAGGCCCATCTGC & 124 \\
\hline Dpt & TCCACAGTTTGAGACACATCCGGT & AGAATGCACTITCATGCTCCACGG & 126 \\
\hline Hoxc9 & ACGCTGGAACTGGAGAAGGAGTTT & TTGACCTGCCGCTCAGTGAGATT & 102 \\
\hline Leptin & ATGTCACCTTGCTTTGGAAGCCAC & ATGTCCCATTGTGGGCAGTACGAT & 96 \\
\hline lgfbp3 & ACAAGGACCTTCCTITGTCAGGCA & AAGTCATCCGGAGAACTAAGCGCA & 113 \\
\hline Tnf-a & AGAACAGCAACTCCAGAACACCCT & TGCCAGTTCCACATCTCGGATCAT & 160 \\
\hline Mcp-1 & TGCTGTCTCAGCCAGATGCAGTTA & TACAGCTTCTTTGGGACACCTGCT & 131 \\
\hline IL-6 & GTGGAAGACAAACCATGTTGCCGT & TATTGCAGGTGAGCTGGACGTTCT & 116 \\
\hline Adiponectin & ATACGATGTGCTTCCTGACTGGCT & TGTTGCCAGTTTCTGTGTGGATGC & 125 \\
\hline IL-10 & AGCACTGCTATGTTGCCTGCTCTT & TGACTGGGAAGTGGGTGCAGTTAT & 95 \\
\hline$\beta$-actin & TGAGCGCAAGTACTCTGTGTGGAT & TAGAAGCATTTGCGGTGCACGATG & 129 \\
\hline
\end{tabular}

Notes: C/ebp $\beta$ CCAAT enhancing binding protein $\beta$, Cidea cell death-inducing DNA fragmentation factor-like effector A, Dio 2 type 2 iodothyronine deiondinase, Dpt dermatopontin, Hoxc9 homeobox C9, Igfbp3 insulin-like growth factor binding protein 3, IL interleukin, Mcp-1 monocyte chemotactic protein-1, Pgc-1a peroxisome proliferative activated receptor gamma coactivator 1 alpha, Tnf-a tumor necrosis factor-a, Ucp-1 uncoupling protein 1 . 
enhanced chemiluminescence, followed by exposure to $\mathrm{X}$-ray. The protein bands on the films were scanned, and the bands density was quantified by densitometric analysis using NIH ImageJ software.

\section{Light microscopic examination}

The adipose tissues of EAT, PAT, WAT and BAT were fixed in formalin, dehydrated, embedded in paraffin, and sectioned for H\&E staining, which were evaluated by light microscopy. For immunohistochemical staining, the deparaffinized sections of adipose tissues $(5 \mu \mathrm{m})$ were subjected to heat-induced antigen retrieval. The slides were dipped into $0.3 \% \mathrm{H}_{2} \mathrm{O}_{2}$ for 10 min to quench the endogenous peroxidase, incubated in $1 \%$ BSA/PBS for $10 \mathrm{~min}$, followed by overnight incubation with primary antibodies(mouse anti-rat CD68 [AbD SeroTec, Raleigh, $\mathrm{NC}]$ ) at $4^{\circ} \mathrm{C}$. Then, the slides were incubated at room temperature for $2 \mathrm{~h}$ with appropriate horseradish peroxidase (HRP)-conjugated rabbit anti-mouse IgGHRP antibody (Santa Cruz Biotechnology). The staining was developed using SIGMAFAST ${ }^{\mathrm{Tm}}$ 3,3'-diaminobenzidine tablet set (Sigma, St Louis, MO). The sections were counterstained with hematoxylin and examined by light microscopy. All measurements were conducted in a double-blinded manner by two independent investigators using a research microscope (Zeiss 510 META, Jena, Germany) with Metamorph V.7.1.2 software (Universal Imaging, West Chester, PA). For immunofluorescence staining, the slides were incubated at room temperature for $2 \mathrm{~h}$ with Alexa Fluor 488 goat anti-rabbit IgG \#4412 (Cell Signaling Technology, Danvers, MA) after incubation with primary antibody against iNOS (Santa Cruz Biotechnology). All measurements were conducted in a double-blinded manner by two independent investigators using a research fluorescence microscope (Nikon, Japan) and NIH ImageJ software.

\section{Transmission electron microscopy (TEM)}

Fresh adipose tissues were excised into small pieces $\left(<1 \mathrm{~mm}^{3}\right)$ and fixed with $2.5 \%$ glutaraldehyde $(0.1 \mathrm{M}$ phosphate buffer, $\mathrm{pH}$ 7.4) for 3 hours. Each specimen was post-fixed in $1 \%$ osmium tetroxide for $1 \mathrm{~h}$ and dehydrated through a graded series of ethanol concentrations before being embedded in Eponate 12 resin, sectioned at a thickness of $80 \mathrm{~nm}$ and stained by $2 \%$ aqueous uranyl acetate followed by lead citrate. The grids were then observed in a Technai G2 Spirit TEM (FEI Company, Hillsboro, OR). Quantitative analysis was carried out at a magnification of 30,000X. Ten visual fields were taken randomly by a senior electron microscopist of the Campus Microscopy and Imaging Facility (CMIF) at The Ohio State University. The average numbers and area of mitochondria from ten visual fields of EAT and PAT were analyzed via NIH ImageJ software.

\section{Bronchoalveolar Lavage}

Total leukocytes in bronchoalveolar fluid were enumerated with a hemocytometer, and fractions of eosinophils, polymorphonuclears, macrophages, and lymphocytes were determined in a cytospin sample stained with Diff-Quick (Dade Behring, Newark, DE).

\section{Statistical analysis}

Values were expressed as mean \pm SEM unless otherwise indicated. For the monofactorial continuous variable, oneway ANOVA was performed to detect the differences between different groups. For the multiple continuous variables with Gauss distribution, two-way ANOVA was performed to detect the differences between different groups, with Bonferroni correction for multiple comparison adjustment. For continuous variables with skewed distribution, the Kruskal-Wallis test was used to detect the differences between the groups. Statistical analysis was performed using SPSS 17.0 (Chicago, IL). All tests were two-tailed, and the differences were considered statistically significant at a $p$ value of $<0.05$.

\section{Abbreviations}

BAT: Interscapular fat; Clebp $\beta$ : CCAAT enhancing binding protein $\beta$; CAPs: Concentrated ambient fine particulates; Cidea: Cell death-inducing DNA fragmentation factor-like effector A; Dio2: Type 2 iodothyronine deiondinase; Dpt: Dermatopontin; EAT: Epicardial adipose tissue; EC: Elemental carbon; HFr: High fructose diet; Hoxc9: Homeobox C9; Igfbp3: Insulin-like growth factor binding protein 3; IL-6: Interleukin-6; iNOS: Inducible nitric oxide synthase; Mcp-1: Monocyte chemotactic protein-1; ND: Normal diet; $\mathrm{O}_{3}$ : Ozone; PAT: Perirenal adipose tissue; OC: Organic carbon; Pgc-1a: Peroxisome proliferative activated receptor gamma coactivator 1 alpha; Tnf-a: Tumor necrosis factor-a; Ucp-1: Uncoupling protein 1; WAT: Visceral fats.

\section{Competing interests}

The authors declare that they have no competing interests.

\section{Authors' contributions}

$L S, C L, X X, Z Y, A M, A W, K A, R P L, L A B, M M, J G W$ and JTD performed the experiments and contributed to acquisition of data. $Z S, L S, C L, J G W, X X, Z Y$, AM and AW analyzed the data and interpreted the results. KA, MM and JTD contributed to CAPs and ozone exposure of the animals. The manuscript was written by LS and revised critically by QS, JGW, SR, JRH, JTD ,RDB, ZF and $X Y, A l l$ authors read, corrected and approved the manuscript.

\section{Acknowledgments}

The authors would like to acknowledge the support from Campus Microscopy and Imaging Facility (CMIF) at The Ohio State University for the TEM experiment. This work was supported by the grants from National Institute of Health and US Environmental Protection Agency (EPA) ES017290, ES019616, and R834797 to Dr. Rajagopalan, ES018900 to Dr. Sun, and EPA STAR R834797 to Drs. Harkema and Rajagopalan.

\section{Author details}

${ }^{1}$ Department of Cardiology, Peking Union Medical College Hospital, Peking Union Medical College \& Chinese Academy of Medical Science, Beijing, China. ${ }^{2}$ Division of Cardiovascular Medicine, The Affiliated Hospital of Chengde Medical College, Chengde Medical College, Chengde, Hebei Province, China. ${ }^{3}$ Department of Physiology, Hangzhou Normal University, Hangzhou, China. ${ }^{4}$ Davis Heart and Lung Research Institute, The Ohio State University, Columbus, Ohio, USA. ${ }^{5}$ Center for Integrative Toxicology and Department of Pathobiology and Diagnostic Investigation, Michigan State University, East Lansing, Michigan, USA. ${ }^{6}$ School of Public Health, University of Michigan, Ann Arbor, Michigan, USA. 'Division of Cardiovascular Medicine, University of Michigan, Ann Arbor, Michigan, USA. 
Received: 24 March 2013 Accepted: 14 August 2013

Published: 22 August 2013

\section{References}

1. Xu Z, Xu X, Zhong M, Hotchkiss IP, Lewandowski RP, Wagner JG, Bramble $L A$, Yang $Y$, Wang $A$, Harkema JR, et al: Ambient particulate air pollution induces oxidative stress and alterations of mitochondria and gene expression in brown and white adipose tissues. Part Fibre Toxicol 2011, 8:20.

2. Walden TB, Petrovic N, Nedergaard J: PPARalpha does not suppress muscle-associated gene expression in brown adipocytes but does influence expression of factors that fingerprint the brown adipocyte. Biochem Biophys Res Commun 2010, 397(2):146-151.

3. lacobellis G, Bianco AC: Epicardial adipose tissue: emerging physiological, pathophysiological and clinical features. Trends Endocrinol Metab 2011, 22(11):450-457.

4. lacobellis G: Epicardial and pericardial fat: close, but very different Obesity (Silver Spring) 2009, 17(4):626-627. 625; author reply.

5. Chong JJ, Chandrakanthan V, Xaymardan M, Asli NS, Li J, Ahmed I, Heffernan C, Menon MK, Scarlett CJ, Rashidianfar A, et al: Adult cardiacresident MSC-like stem cells with a proepicardial origin. Cell Stem Cell 2011, 9(6):527-540.

6. Verhagen SN, Visseren FL: Perivascular adipose tissue as a cause of atherosclerosis. Atherosclerosis 2011, 214(1):3-10.

7. de Vos AM, Prokop M, Roos CJ, Meijs MF, van der Schouw YT, Rutten A, Gorter PM, Cramer MJ, Doevendans PA, Rensing BJ, et al: Peri-coronary epicardial adipose tissue is related to cardiovascular risk factors and coronary artery calcification in post-menopausal women. Eur Heart J 2008, 29(6):777-783.

8. Bucci M, Joutsiniemi E, Saraste A, Kajander S, Ukkonen H, Saraste M, Pietila M, Sipila HT, Teras M, Maki M, et al: Intrapericardial, but not extrapericardial, fat is an independent predictor of impaired hyperemic coronary perfusion in coronary artery disease. Arterioscler Thromb Vasc Biol 2011, 31(1):211-218.

9. Pancras JP, Landis MS, Norris GA, Vedantham R, Dvonch JT: Source apportionment of ambient fine particulate matter in Dearborn, Michigan, using hourly resolved PM chemical composition data. The Science of the total environment 2013, 448:2-13.

10. Pinsky DJ, Cai B, Yang X, Rodriguez C, Sciacca RR, Cannon PJ: The lethal effects of cytokine-induced nitric oxide on cardiac myocytes are blocked by nitric oxide synthase antagonism or transforming growth factor beta. J Clin Invest 1995, 95(2):677-685.

11. Malavazos AE, Di Leo G, Secchi F, Lupo EN, Dogliotti G, Coman C, Morricone L, Corsi MM, Sardanelli F, lacobellis G: Relation of echocardiographic epicardial fat thickness and myocardial fat. Am J Cardiol 2010, 105(12):1831-1835.

12. lacobellis G, Willens HJ, Barbaro G, Sharma AM: Threshold values of high-risk echocardiographic epicardial fat thickness. Obesity (Silver Spring) 2008, 16(4):887-892.

13. Cheng KH, Chu CS, Lee KT, Lin TH, Hsieh CC, Chiu CC, Voon WC, Sheu SH, Lai WT: Adipocytokines and proinflammatory mediators from abdominal and epicardial adipose tissue in patients with coronary artery disease. Int J Obes (Lond) 2008, 32(2):268-274.

14. lacobellis G, Leonetti F: Epicardial adipose tissue and insulin resistance in obese subjects. J Clin Endocrinol Metab 2005, 90(11):6300-6302.

15. Lin SC, Li P: CIDE-A, a novel link between brown adipose tissue and obesity. Trends Mol Med 2004, 10(9):434-439.

16. Chatterjee TK, Stoll LL, Denning GM, Harrelson A, Blomkalns AL, Idelman G, Rothenberg FG, Neltner B, Romig-Martin SA, Dickson EW, et al: Proinflammatory phenotype of perivascular adipocytes: influence of high-fat feeding. Circ Res 2009, 104(4):541-549.

17. Barber MC, Ward RJ, Richards SE, Salter AM, Buttery PJ, Vernon RG, Travers MT: Ovine adipose tissue monounsaturated fat content is correlated to depot-specific expression of the stearoyl-CoA desaturase gene. J Anim Sci 2000, 78(1):62-68.

18. Sacks HS, Fain JN, Holman B, Cheema P, Chary A, Parks F, Karas J, Optican R, Bahouth SW, Garrett E, et al: Uncoupling protein-1 and related messenger ribonucleic acids in human epicardial and other adipose tissues: epicardial fat functioning as brown fat. J Clin Endocrinol Metab 2009, 94(9):3611-3615
19. Kremen J, Dolinkova M, Krajickova J, Blaha J, Anderlova K, Lacinova Z, Haluzikova D, Bosanska L, Vokurka M, Svacina S, et al: Increased subcutaneous and epicardial adipose tissue production of proinflammatory cytokines in cardiac surgery patients: possible role in postoperative insulin resistance. J Clin Endocrinol Metab 2006, 91(11):4620-4627.

20. Lin YK, Chen YC, Chang SL, Lin YJ, Chen JH, Yeh YH, Chen SA, Chen YJ: Heart failure epicardial fat increases atrial arrhythmogenesis. Int J Cardiol 2012 [Epub ahead of print].

21. Fain JN, Sacks HS, Bahouth SW, Tichansky DS, Madan AK, Cheema PS: Human epicardial adipokine messenger RNAs: comparisons of their expression in substernal, subcutaneous, and omental fat. Metabolism 2010, 59(9):1379-1386.

22. Gesta S, Bluher M, Yamamoto Y, Norris AW, Berndt J, Kralisch S, Boucher J, Lewis C, Kahn CR: Evidence for a role of developmental genes in the origin of obesity and body fat distribution. Proc Natl Acad Sci USA 2006, 103(17):6676-6681.

23. Xu X, Liu C, Xu Z, Tzan K, Wang A, Rajagopalan S, Sun Q: Altered adipocyte progenitor population and adipose-related gene profile in adipose tissue by long-term high-fat diet in mice. Life Sci 2012, 90(25-26):1001-1009.

24. Ricquier D: Respiration uncoupling and metabolism in the control of energy expenditure. Proc Nutr Soc 2005, 64(1):47-52.

25. Klingenberg M, Huang SG: Structure and function of the uncoupling protein from brown adipose tissue. Biochim Biophys Acta 1999, 1415(2):271-296.

26. Farmer SR: Molecular determinants of brown adipocyte formation and function. Genes Dev 2008, 22(10):1269-1275

27. Ito M, Nagasawa M, Omae N, Ide T, Akasaka Y, Murakami K: Differential regulation of CIDEA and CIDEC expression by insulin via Akt1/2- and JNK2-dependent pathways in human adipocytes. J Lipid Res 2011, 52(8):1450-1460.

28. Christoffolete MA, Linardi CC, de Jesus L, Ebina KN, Carvalho SD, Ribeiro MO, Rabelo R, Curcio C, Martins L, Kimura ET, et al: Mice with targeted disruption of the Dio2 gene have cold-induced overexpression of the uncoupling protein 1 gene but fail to increase brown adipose tissue lipogenesis and adaptive thermogenesis. Diabetes 2004, 53(3):577-584

29. Boney CM, Moats-Staats BM, Stiles AD, D'Ercole AJ: Expression of insulinlike growth factor-I (IGF-I) and IGF-binding proteins during adipogenesis. Endocrinology 1994, 135(5):1863-1868.

30. Gauldie J, Northemann W, Fey GH: IL-6 functions as an exocrine hormone in inflammation. Hepatocytes undergoing acute phase responses require exogenous IL-6. J Immunol 1990, 144(10):3804-3808.

31. Jerrett M, Burnett RT, Pope CA 3rd, Ito K, Thurston G, Krewski D, Shi Y, Calle E, Thun M: Long-term ozone exposure and mortality. The New England journal of medicine 2009, 360(11):1085-1095.

32. Rodriguez A, Fortuno A, Gomez-Ambrosi J, Zalba G, Diez J, Fruhbeck G: The inhibitory effect of leptin on angiotensin II-induced vasoconstriction in vascular smooth muscle cells is mediated via a nitric oxide-dependent mechanism. Endocrinology 2007, 148(1):324-331.

33. Thomson E, Kumarathasan P, Goegan P, Aubin RA, Vincent R: Differential regulation of the lung endothelin system by urban particulate matter and ozone. Toxicol Sci 2005, 88(1):103-113.

34. Kodavanti UP, Thomas R, Ledbetter AD, Schladweiler MC, Shannahan JH, Wallenborn JG, Lund AK, Campen MJ, Butler EO, Gottipolu RR, et al: Vascular and cardiac impairments in rats inhaling ozone and diesel exhaust particles. Environmental health perspectives 2011, 119(3):312-318.

35. Jeong Jl, Park SU: Interaction of gaseous pollutants with aerosols in Asia during March 2002. The Science of the total environment 2008, 392(2-3):262-276.

36. Moore KJ, Tabas I: Macrophages in the pathogenesis of atherosclerosis. Cell 2011, 145(3):341-355.

37. Mazurek T, Zhang L, Zalewski A, Mannion JD, Diehl JT, Arafat H, Sarov-Blat L, O'Brien S, Keiper EA, Johnson AG, et al: Human epicardial adipose tissue is a source of inflammatory mediators. Circulation 2003, 108(20):2460-2466.

38. Morishita MKG, Kamal AS, Wagner JG, Harkema JR, Rohr AC: Source identification of ambient PM2.5 for inhalation exposure studies in Steubenville, Ohio using highly time-resolved measurements. Atmos Environ 2011, 45(40):9.

39. Tran LT, Yuen VG, McNeill JH: The fructose-fed rat: a review on the mechanisms of fructose-induced insulin resistance and hypertension. Molecular and cellular biochemistry 2009, 332(1-2):145-159. 
40. Sioutas $C$, Koutrakis $P$, Burton RM: $A$ technique to expose animals to concentrated fine ambient aerosols. Environmental health perspectives 1995, 103(2):172-177.

41. Harkema JR, Keeler G, Wagner J, Morishita M, Timm E, Hotchkiss J, Marsik F, Dvonch T, Kaminski N, Barr E: Effects of concentrated ambient particles on normal and hypersecretory airways in rats. Res Rep Health Eff Inst 2004 120:1-68. discussion 69-79.

42. Rohr AC, Kamal A, Morishita M, Mukherjee B, Keeler GJ, Harkema JR, Wagner $J G$ : Altered heart rate variability in spontaneously hypertensive rats is associated with specific particulate matter components in Detroit, Michigan. Environmental health perspectives 2011, 119(4):474-480.

doi:10.1186/1743-8977-10-43

Cite this article as: Sun et al:: Ambient fine particulate matter and ozone exposures induce inflammation in epicardial and perirenal adipose tissues in rats fed a high fructose diet. Particle and Fibre Toxicology 2013 10:43

\section{Submit your next manuscript to BioMed Central and take full advantage of:}

- Convenient online submission

- Thorough peer review

- No space constraints or color figure charges

- Immediate publication on acceptance

- Inclusion in PubMed, CAS, Scopus and Google Scholar

- Research which is freely available for redistribution 